\title{
Nanofabrication Techniques in Large-Area Molecular Electronic Devices
}

\author{
Lucía Herrer ${ }^{\mathbb{D}}$, Santiago Martín $(\mathbb{D}$ and Pilar Cea *(D) \\ Departamento de Química Física, Facultad de Ciencias, Universidad de Zaragoza, Pedro Cerbuna 12, \\ 50009 Zaragoza, Spain; lucia.h@unizar.es (L.H.); smartins@unizar.es (S.M.) \\ * Correspondence: pilarcea@unizar.es
}

Received: 30 July 2020; Accepted: 27 August 2020; Published: 1 September 2020

\begin{abstract}
The societal impact of the electronics industry is enormous-not to mention how this industry impinges on the global economy. The foreseen limits of the current technology-technical, economic, and sustainability issues-open the door to the search for successor technologies. In this context, molecular electronics has emerged as a promising candidate that, at least in the short-term, will not likely replace our silicon-based electronics, but improve its performance through a nascent hybrid technology. Such technology will take advantage of both the small dimensions of the molecules and new functionalities resulting from the quantum effects that govern the properties at the molecular scale. An optimization of interface engineering and integration of molecules to form densely integrated individually addressable arrays of molecules are two crucial aspects in the molecular electronics field. These challenges should be met to establish the bridge between organic functional materials and hard electronics required for the incorporation of such hybrid technology in the market. In this review, the most advanced methods for fabricating large-area molecular electronic devices are presented, highlighting their advantages and limitations. Special emphasis is focused on bottom-up methodologies for the fabrication of well-ordered and tightly-packed monolayers onto the bottom electrode, followed by a description of the top-contact deposition methods so far used.
\end{abstract}

Keywords: molecular electronics; self-assembly films; Langmuir-Blodgett films; electrografting; top-contact electrode

\section{Introduction}

The impact of the omnipresent Complementary Metal-Oxide Semiconductor (CMOS) electronic industry on the global economy is enormous, due to its role not only in the production of computers, mobiles, tablets, etc., but mainly as an essential component in products from many other industries (automobile, aeronautics, artificial satellites, trains, security and armies, communication systems, computer science, robotics, energy, financial services, diagnostic equipment in hospitals, booster of the Research, Development, and innovation, etc.). Thus, the global market for electronic components is expected to grow in the 2020-2025 period at a compound annual growth rate of ca. $4.8 \%$ [1]. The new scenario imposed by the COVID-19 pandemic has further evidenced the relevance of the electronic industry in our society. Could the reader imagine how the months of confinement would have been like without the internet, teleconferencing, online teaching, streaming videos, online shopping, etc.?

If we look back over the historical development of the electronic industry, the last four decades have witnessed enormous and rapid progress in the miniaturization of electronic devices (Moore law) from $3 \mu \mathrm{m}$ transistors in 1980 to the current $7 \mathrm{~nm}$ technology already in the market, using the FinfET (Fin Field-effect Transistor) technology, with microprocessors that incorporate more than 50 billion transistors and pursuing the $5 \mathrm{~nm}$ transistor in 2020. This miniaturization is accompanied by a reduction in the global size and weight of electronic components, an increase in switching performance and 
faster processors, an increase in logic area efficiency, as well as a decrease in the energy consumption and consequently longer battery life. It is expected that if the surface area of a transistor decreases by two every two years (reduction of the lateral size by 1.4), the $3 \mathrm{~nm}$ technology could appear in 2022 (the міт has created a $2.5 \mathrm{~nm}$ transistor [2]), and by 2024, $1 \mathrm{~nm}$ transistors might emerge. There are, however, a number of associated technological problems within this miniaturization race that will need to be overcome for these predictions to be reached. In devices thinned to a few nanometers, quantum effects governing the electron behavior appear, which can make transistors unreliable, due to the quantum uncertainties [3]. The reduction in the size of transistors is also associated with a dramatic increase in the fabrication process costs (second Moore law) which has resulted in a drastic decrease of foundries (from 20 foundries for $130 \mathrm{~nm}$ technology to only four major companies providing transistors in the 10 to $7 \mathrm{~nm}$ range), which is ultimately reflected in the cost of electronic devices in the market and could make future nodes unaffordable, due to the manufacturing costs for ultra-large-scale implementation [4]. Additionally, when an increasing number of transistors are ensemble into a small area of a single piece of an integrated circuit, inelastic scattering of electrons [5] results in waste-heat that emerges as an additional problem as chips get too hot, which requires efficient heat dissipation systems [3].

The technological and economic limits of the current cmos technology are therefore imminent, and scientists all over the world are working on alternative technologies, due to the continual and growing social demand for more efficient, more rapid, more versatile, and low-power devices, not to mention flexible electronics. In 2016, the eighteen years old ITRs [6] (International Technology Roadmap for Semiconductors) was renamed as IRDs [7] (International Roadmap for Devices and Systems), which is a clear reflection of the need of alternative technologies in the XXI century. A potential successor of our current technology, must not only fulfill the same expectations as смоs but also outperform prevalent technology in at least a number of several clue aspects, including power consumption, mass production, fabrication costs, and performance, and overcome current functionalities, i.e., fully enter in the "More than Moore" path [8]. These efforts are being made from a multidisciplinary point of view, for which the contribution of physicists, chemists, and engineers is essential for overcoming the enormous challenges ahead.

In the above-described scenario, molecular electronics emerges as a great promise. Molecular electronics is based on the idea of using molecules as functional units in circuitry to permit, control, and manipulate the movement of electrical charges between two electrodes [9]. The fundamental tool for understanding electrical transport through these two electrodes is the creation of electrode | molecule | electrode molecular junctions [10-14]. The official birth of molecular electronics is widely recognized as 1974, with the publication of the seminal paper from Aviran and Ratner that proposed (theoretically) that a single-molecule could act as a rectifier [15]. Intense work in the field for more than four decades has included the development of methodologies based on scanning tunneling microscopy (STM) or conducting atomic force microscopy (C-AFM) for measuring the electrical properties of single-molecules and molecular assemblies [14,16-22]. These studies have resulted in a growing understanding of the key parameters that determine the electrical properties of molecular junctions (molecular backbone [12,23], chemical anchoring groups [24-26], conformation [27], metal complexation [28], redox state [18,29-31], electrode material [32-35], and if applicable, the characteristics of the medium: Solvent [36], pH [37], etc.), as well as the mechanisms behind electronic transport in molecular junctions [38-40]. In particular, molecular wires [41], switches [42], diodes [43], rectifiers [44], transistors [45], and single-molecule light-emitting diodes [46] have already been demonstrated in the laboratory and make feasible the idea of integrating molecules into electrical circuits. The expectations in molecular electronics lie on its several advantages as compared to the above-described Si-based technology with relevant contributions in the field [47-50], making emphasis on applications of molecular electronics in solar-energy harvesting, thermoelectricity, catalysis, or molecular sensing. Another field of remarkable importance today is the study of single-molecule chemical reactions within the molecular junction [51-53]. The use of molecules has several advantages - both from a fundamental and an applied point of view. The most remarkable 
phenomena observed in molecular junctions and their promising perspectives in a short-term future technology result from:

- The size of the molecules-in the order of a few nanometers-that may enable heightened capacities, faster performance, and high integration density, with millions of identical electric machines each of them as small as one molecule [50].

- Molecular junctions exhibit a plethora of rich and tunable physicochemical properties-different from those exhibited by molecular materials in bulk-since charge transport is governed by quantum mechanics at the molecular scale. These phenomena at the nanoscale include quantum mechanical interference, the Coulomb blockade, and the Kondo effect [12,54].

- The versatility of organic chemistry to produce millions of identical functional units (molecules)—estimated in $10^{60}$ molecules with 15 atoms or fewer [51]—is expected to result in not only in low-cost manufacturing, due to self-assembly (SA) capabilities, but also in thinner and low-weight devices, lower supply-voltages [51], as well as a large variety of new and distinctive functionalities provided by molecules (optical, magnetic, thermoelectric, electromechanical, etc.), which are often not possible by employing conventional materials [10].

- Redox-active molecular components can be addressed and 'switched' through the introduction of a third 'gate' electrode [45,55-57]. In this field, exploration of the molecular structure, ligands, inclusion of different metal clusters, control of electrochemical gating together with the potential for modular construction [58] may have relevant implications in the field of molecular electronics.

- The properties of (magnetic) molecules together with control over the spin state of molecular devices by tuning the interaction of the localized orbitals of the molecule with the electronic states of the electrode also open the door to the exploration and control of spin transport phenomena and spintronic applications, e.g., switches and qubits [59-62]. In addition, the study of magnetic spins on a molecule connected to a superconducting electrode represents a fascinating topic of interest today [63].

- One of the most promised envisioned applications of molecular electronics is thermoelectrics, i.e., efficient conversion of heat to electricity [64]. Fabrication of ultrahigh-efficient thermoelectric power generators as small as one molecule is possible, and could potentially be used to build ultrahigh-efficient thermoelectric power generators [64-66]. These power converters could reuse and recycle the dissipation heat produced by (molecular) electronic devices into electricity to (partially) supply the power required to operate the device, resulting in a meaningful decrease in electric power consumption [67], and also in applications for on-chip cooling in nanoscale electronic devices [68].

- The combined use of organic molecules and carbon-based or polymeric-based materials as electrodes could pave the road towards not only flexible devices $[33,69]$, but also to biocompatible electronics [70] and also lead to more sustainable fabrication processes, reduce e-waste and culminate in the development of electronics that self-degrade after service life [71].

Two different paradigms have attracted the interest of researchers in the field of molecular electronics. On the one hand, the study of single-molecule junctions, i.e., electrode $\mid$ molecule $\mid$ electrode, is of fundamental importance for the understanding of charge transport, as well as the different factors that determine the electrical properties of these junctions, Figure 1a. Thus, it is well known that the molecular structure, the anchoring groups, the presence of metal or redox moieties, etc. can strongly determine charge transport at the molecular level. However, fabrication of these single molecular junctions with our current technology is not a scalable process, which seriously hampers the incorporation of molecular electronics into the market. On the other hand, the study of large-area devices, i.e., electrode | molecular assembly | electrode, has gained attention in the last years. Here, collective effects (intermolecular forces and polarization phenomena), induced by the close packing of the molecules in the monolayer, may determine the electrical behavior of these systems, which opens the door to finding new effects and also to tune the properties of the devices by an exhaustive control 
of interactions between neighbor molecules, Figure 1b. Additionally, these molecular assemblies allow the manufacture of devices with a surface density of up to $10^{15}$ molecules $\cdot \mathrm{cm}^{-2}$. Importantly, the deposition of molecules onto the electrode can be carried out using simple and scalable technologies that allow high-quality and reproducible assemblies, making possible the manufacture of thousands of devices. This potential processability and scalability in the fabrication of large-area molecular electronic devices are much more appealing for industrial processes opening the door towards industrial mass production. Here, it is encouraging to note that a molecular electronic device for audio processing has already been commercialized [72], albeit briefly. Therefore, the translation of such science to a viable technology for industrial applications is an active goal today, with a considerable number of scientific and technological challenges [73] remaining to be met, as indicated below. Such incorporation of molecules into hard electronics will probably take place, at least in a first stage, in combination with traditional silicon-based current technologies. An optimization of interface engineering has been recently named as "the most challenging issue that hampers the development of reliable molecular junctions" in a recent review published in Nature Reviews Physics [13]. Such technology should be able to optimize the molecule-electrode contacts oriented to mass production of high yield, robust, stable, scalable, and reproducible devices to be produced at a reasonable cost. The optimization of the electrode | molecule interface (Figure 1c) involves several aspects:

(i) Coupling of the molecule to the electrode surface through the contacting group, which plays a crucial role and has prompted an extensive search for chemical groups that can effectively serve as molecular 'anchor groups' [25,28,35,74-78];

(ii) Mechanical stability of the electrode molecular junction avoiding fluxional bonds $[79,80]$. Several strategies have been employed for this purpose, including the use of multidentate anchor groups [57,81], and multipodal platforms [82];

(iii) Compromise between the mechanical stability and electronic coupling since a too strong interface coupling may result in the loss of electrical functionalities and also in poor gating effects in three-terminal structures. This compromise could be reached by the insertion of a spacer between the anchoring group and the conjugated skeleton within the molecular structure [13];

(iv) Control of the geometry of molecules to avoid fluctuations, due to different orientations (and then a different distance for the electrons tunneling between the electrodes), which can be achieved by an exhaustive control of the surface coverage and molecular packing density [83].

(v) Control of lateral interactions and aggregation effects in molecular assemblies. These lateral intermolecular interactions may have a decisive role in the electron transport properties of large-area devices based on $\pi$-conjugated materials [22];

(vi) Deposition of the top contact electrode avoiding the formation of short-circuits and/or damage of the functional organic molecules in the monolayer [84,85].

Taking into account this scenario, consideration is now being given to device fabrication strategies (deposition of a monolayer onto the bottom electrode and deposition of the top contact electrode onto the monolayer) for the construction of large-area devices that could progress the integration of the concepts of single-molecule electronics towards viable large-area devices. The objective of this focused review, with no claims of completeness, is to describe the most widely used strategies for the deposition of a monolayer onto the bottom electrode, as well as an overview of the top-contact deposition methods explored so far. 
a)

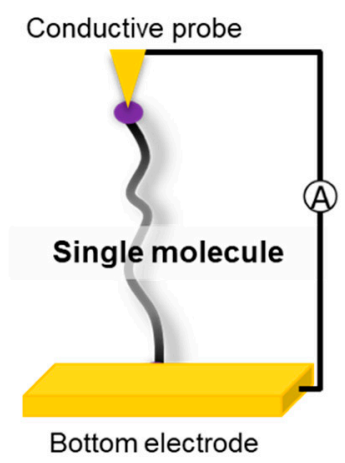

b)

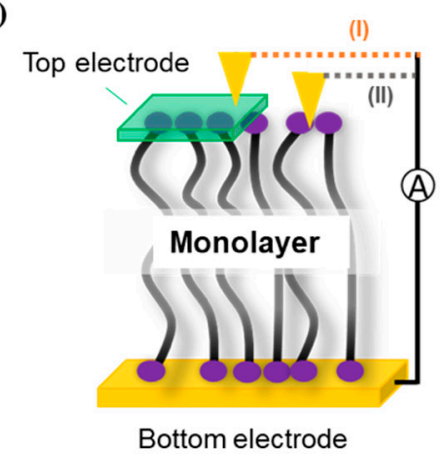

c)

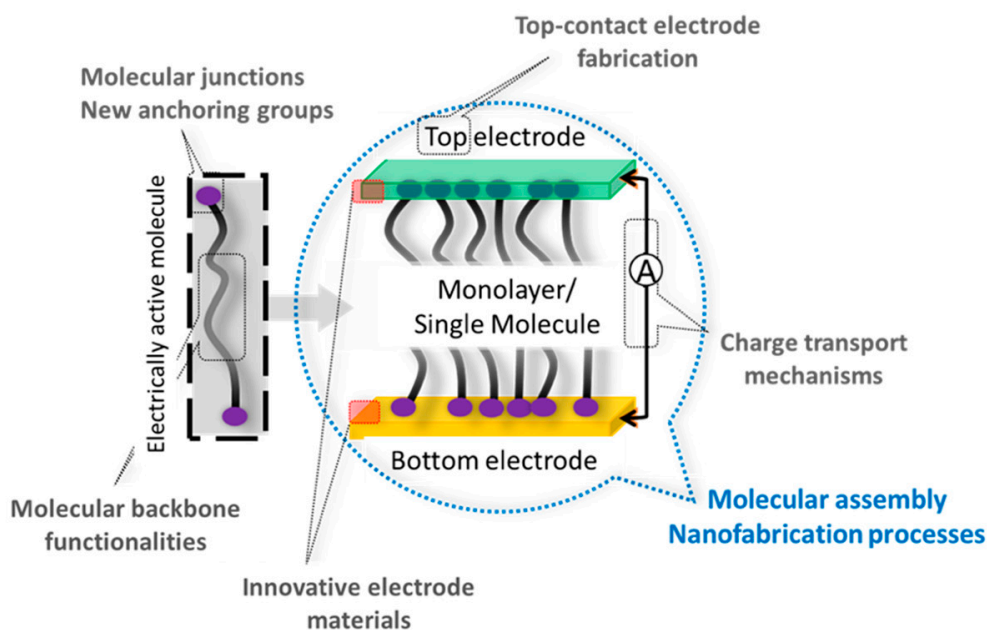

Figure 1. (a) Scheme of a molecular device based on single-molecule junctions. The electrical contact is made directly with a conductive probe. (b) Scheme of a sandwiched large-area molecular device. The electrical contact can be made using a top-contact electrode (I), which is more oriented to mass production, or directly above the organic monolayer (II), to determine the electrical properties of the electrode | monolayer structure. (c) Main challenges to be addressed in molecular electronics.

\section{Fabrication of Molecular Films, Deposition Techniques}

Nanofabrication of monolayers for the construction of vertical devices has attracted considerable attention in the field of molecular electronics, in particular by those working on the large-area device paradigm. An overview of the fabrication methodologies for these large-area methodologies is the scope of this section. A well-ordered monolayer sandwiched between two electrodes is the fundamental element to be studied in this field, with many seminal works establishing key structure-property relationships through the construction and study of electrode | monolayer | electrode system (molecular junctions). For this reason, bottom-up techniques-in which forces acting at the nanoscale are used to assemble molecules into large assemblies-have been widely employed for the deposition of a monolayer onto the bottom electrode and will be revised in this section. The most widely used techniques for the construction of electrode $\mid$ monolayers in the context of molecular electronics include the Self-assembly (SA), the Langmuir-Blodgett (LB), and the Electrografting (EG) methods. Because of the remarkable ensemble capabilities of each one of these techniques, monolayers or multilayers made of organic, organometallic, hybrid inorganic-organic building blocks, as well as biomaterials have been deposited onto conducting or semiconducting substrates. In addition, the growing knowledge on the electrode | monolayer interface, together with the mature synthetic expertise in this research field, has boosted the ad hoc synthesis of materials with improved anchoring characteristics onto the bottom-electrodes [35,82,86-91]. Table 1, gathers, with no claim of completeness, some of the families of compounds that have been more widely used for fundamental studies in molecular electronics. 
Table 1. Illustrative examples of molecular skeletons and anchor groups of the main families of materials used to fabricate molecular films in the field of molecular electronics.

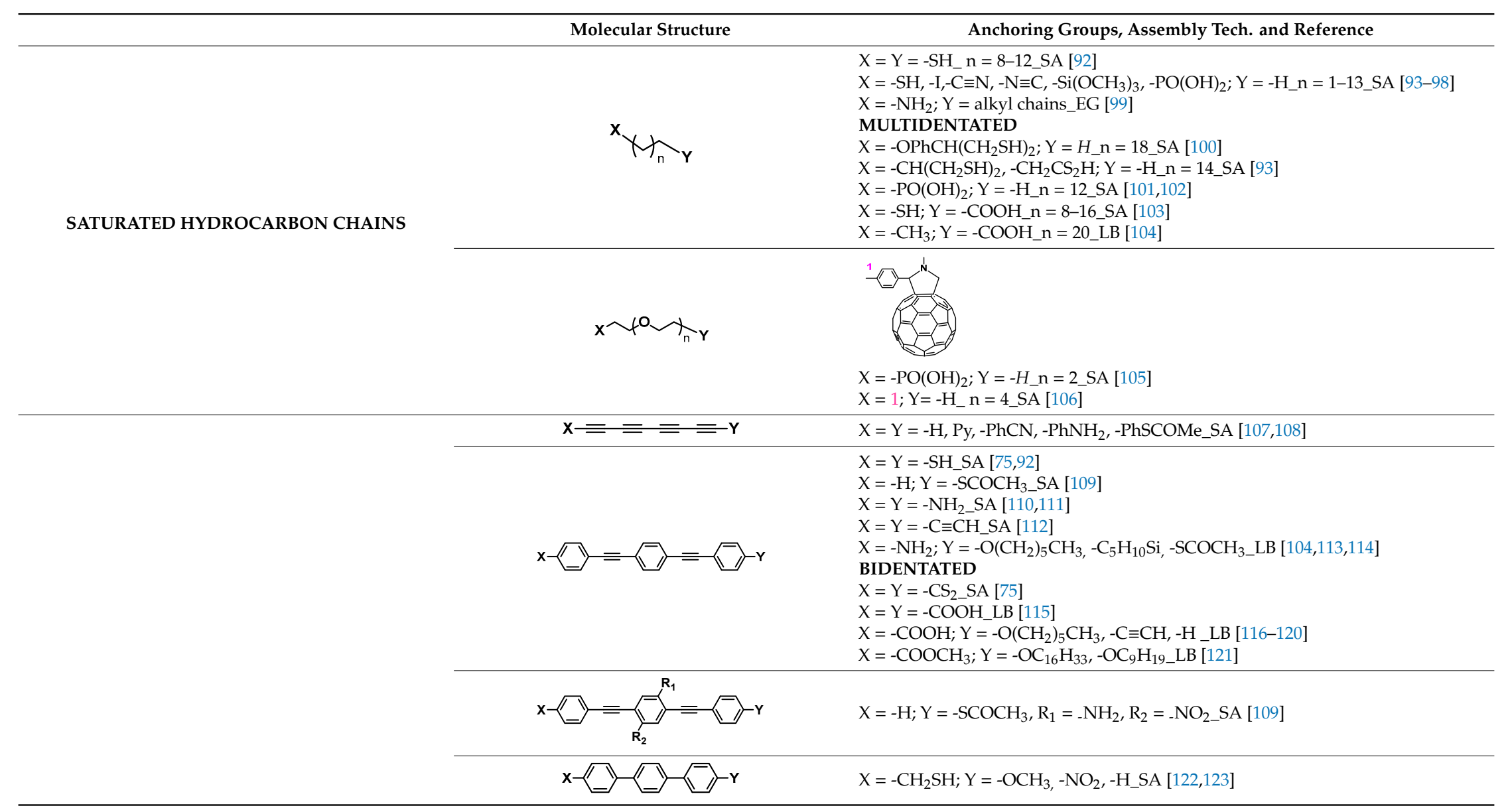


Table 1. Cont.

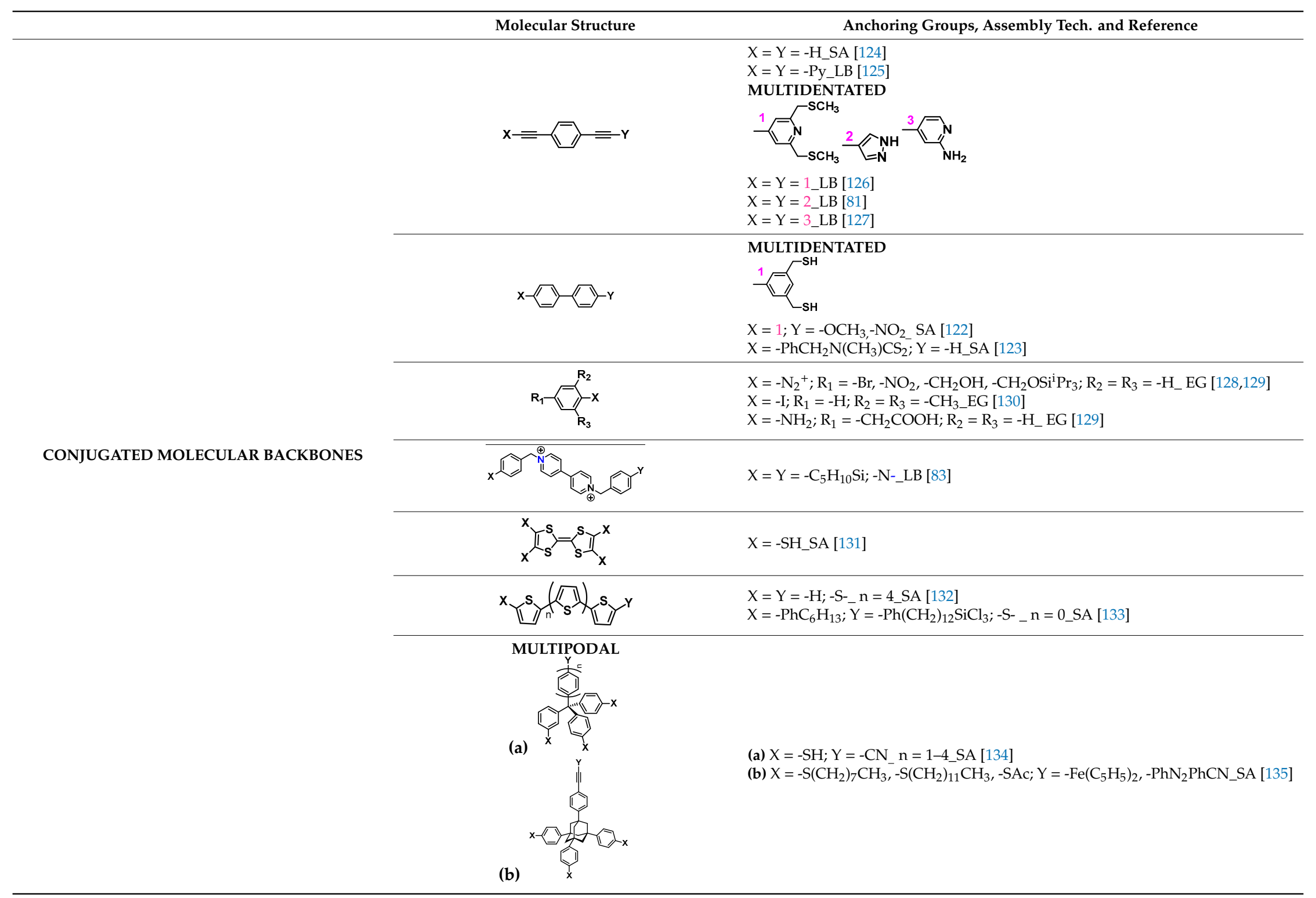


Table 1. Cont.

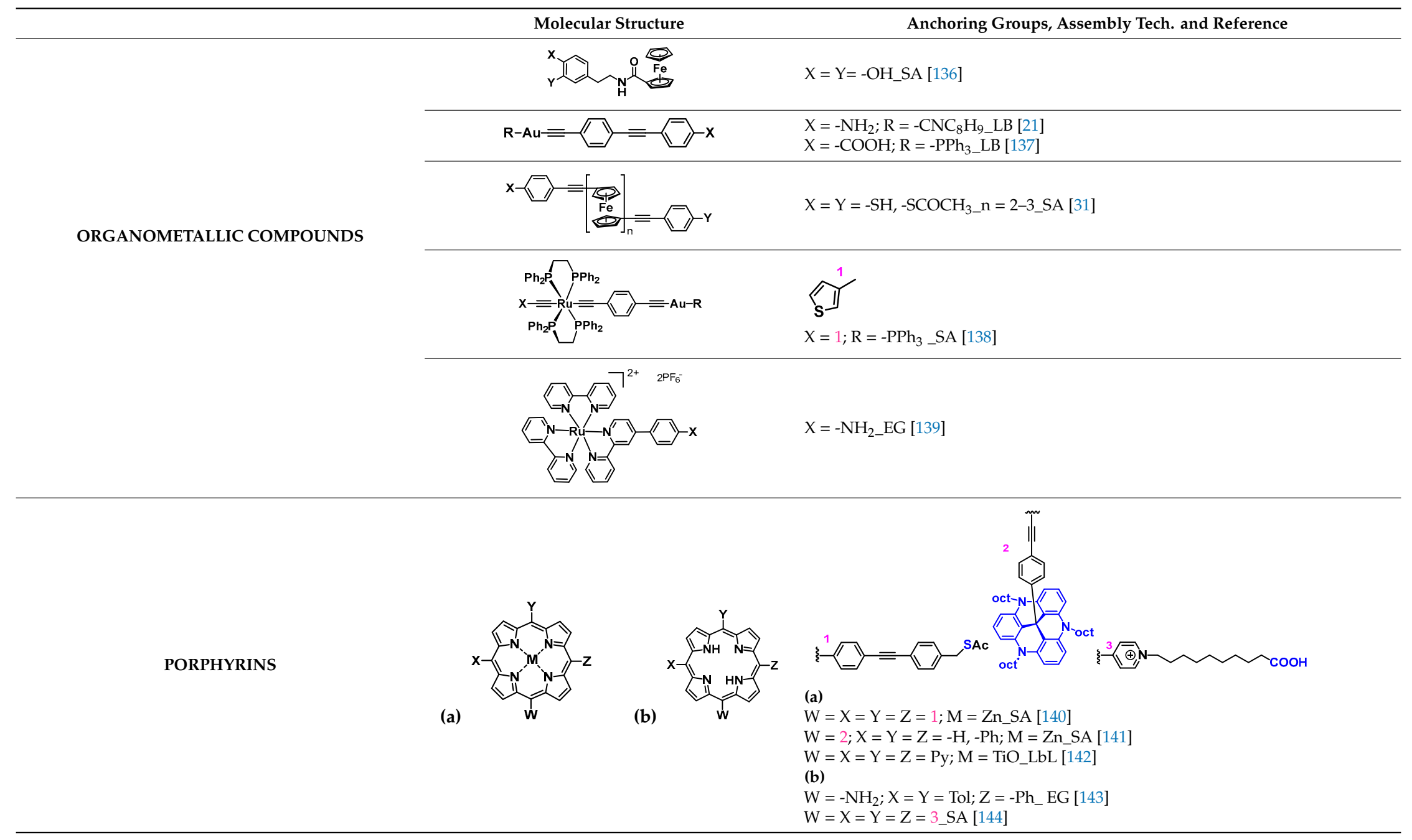


Table 1. Cont.

\begin{tabular}{lll}
\hline Molecular Structure & Anchoring Groups, Assembly Tech. and Reference \\
CARBONACEOUS MATERIALS & (a) CNTs & (b) rGO \\
BIOMOLECULES & (a) DNA & $\begin{array}{l}\text { (a) LS [145] } \\
\text { (b) LB [146] }\end{array}$ \\
\hline
\end{tabular}




\subsection{The Self-Assembly Technique}

The self-assembly technique is based on the autonomous and spontaneous reaction of a certain functional group on a surface (chemisorption) [150] and subsequent organization of the backbone of the molecule, due to non-covalent lateral intermolecular forces between neighbor molecules, resulting in long-range molecularly ordered domains within the monolayer. The cooperative effect of this strong-soft combination of forces often results in dynamic behavior of the molecules in the self-assembly monolayer (SAM), exhibiting lateral diffusion, conformational isomerism, and even reconstruction [151].

A general procedure for SAMs fabrication is illustrated in Figure 2. The substrate (e.g., Au, $\mathrm{Ag}, \mathrm{Pt}, \mathrm{Cu}, \mathrm{Pd}, \mathrm{SiO}_{2}$, etc.) is introduced in an organic solution containing the molecule of interest (typically in the $10 \mu \mathrm{M}$ to $10 \mathrm{mM}$ range). A previous thorough cleaning process of the substrate is required, and often, a pre-treatment of the surface is also applied (annealing, plasma, etching, etc.). After a certain incubation time, the sample is withdrawn from the solution and exhaustively rinsed to remove any physisorbed material. In order to obtain high-quality monolayers with a large surface coverage, it is necessary to optimize a number of influential parameters, such as the incubation time, the concentration, the solvent, the temperature or the ambient relative humidity, due to the water adsorption on the surface of the substrate prior to the immersion into the solution containing the molecule of interest [152,153].

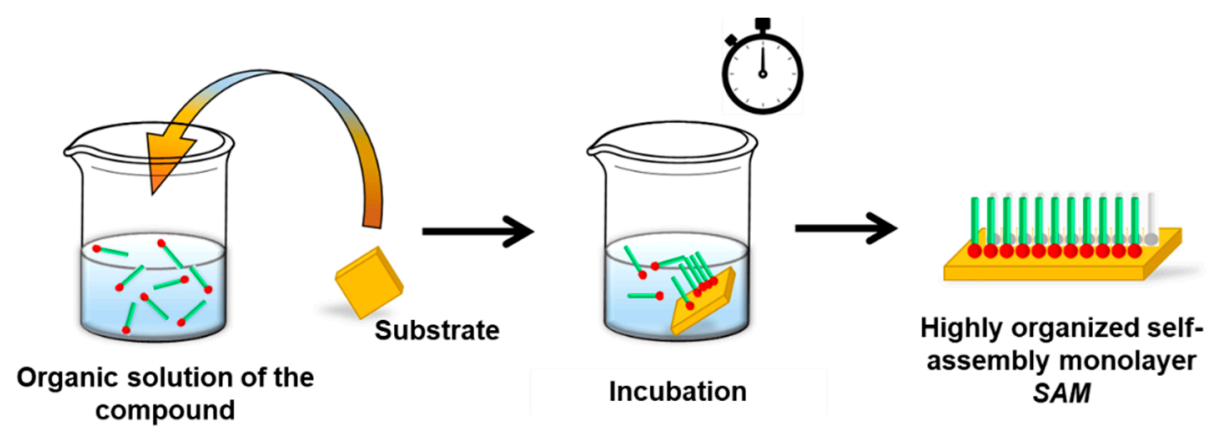

Figure 2. Scheme that illustrates the procedure for the preparation of a self-assembled monolayer. First, a clean substrate is incubated in a solution containing the molecules of interest for a certain time. Second, the substrate is withdrawn and thoroughly rinsed to remove the physisorbed material.

The self-assembly method has been widely used [154-156] in the field of molecular electronics since it is probably the most useful approach for the fabrication of well-organized and tightly-packed monolayers, due to its simplicity and versatility. The main advantages of the self-assembly methodology include:

- Fabrication of high-quality monolayers exhibiting 2D-crystalline long-range molecularly ordered regions.

- Low-cost process: (i) No specific instrumentation is required; (ii) it takes place under ambient conditions (no annealing neither low pressures required); (iii) no significant contamination problems occur upon the monolayer fabrication; (iv) the process is quite straightforward for the operator.

- The SA method is easily scalable.

- The assembly process can be in situ followed by a quartz crystal microbalance, QCM, that provides information about the deposition rate and surface coverage.

- Further functionalization of the monolayer either to form multi-layered films [157] or to deposit the top-contact electrode trough a strong molecule-electrode interaction is possible by an appropriate design of the material with the inclusion of a terminal group with the desired functionality. 
Chemisorption is highly specific in nature, and therefore, the terminal functional group of the organic moiety needs to be carefully designed to find a compromise between the strength of the anchoring process on the surface and the final performance of the electrode | monolayer junctions [158].

In the self-assembly methodology, the main limitation comes from the number of functional groups showing the specific affinity and robust interactions with the electrode. As a consequence, a vast majority of the SAMs for molecular electronics incorporate molecules having a thiolate derivative as the head group interacting with the metal substrate [159-175]. In fact, most of the pioneering work in the study of electrical properties of molecules done in the late 1990s and early years of the 21st century was based on thiol on gold contacts [176-179]. These seminal works served to set the basis of the methods to measure the electrical properties of both single-molecules and ensembles of molecules and also to demonstrate the viability of using molecules as basic elements in circuitry. However, the $\mathrm{Au}-\mathrm{S}$ bond is fluxional and not very stable, which explains some of the reproducibility problems encountered in the literature $[92,109]$. Additionally, other drawbacks to the thiol on gold SA technique have been reported, such as the tendency of organic thiols to oxidize to disulfides; this problem can be overcome by using protected thiols, but the incorporation of extraneous material within the system when in situ deprotection steps are involved may also affect the final electrical properties of the system [180]. The chemical reactivity and thermal stability of these systems in ambient and aqueous solutions have also been reported to seriously limit the technological applications of thiol and dithiol monolayers on gold [161]. Moreover, a recent contribution has revealed that SAMs prepared from the solution deposition of dithiols do not have a chemisorbed character [181]. For these reasons, many other anchor groups have been studied in the last two decades on different substrates $\left(\mathrm{SiO}_{2}, \mathrm{Cu}, \mathrm{Ag}, \mathrm{Au}, \mathrm{WO}_{3}\right.$, and ITO-indium tin oxide-among others), including selenols [94], amines [110,111], cyanides and isocyanides [95,96], isothiocyanates [182], trimethylsilyl group [183,184], acetylenes [107,112,124,185], thiophenes [132,186], trichlorosilanes [133], trimethoxysilanes [97,142], phosphonate [98,105] terminated molecules, perylenes [187], and fullerenes [106,188,189]. Recently, Qiu et al. [106] reported the spontaneous formation of molecular junctions of glycol ether functionalized fullerenes on $\mathrm{Au}^{\mathrm{TS}}$, which resulted in the large stability and robustness of the SAMs.

As it was mentioned before in the introduction section of this review, much interest has been paid recently to the use of SAMs incorporating multidentated anchor groups [190] that are expected to provide additional robustness to the molecular junction, lower fluctuation defects, more efficient electronic coupling, and enhanced electrical performance [26,170]. In this context dithiols [100,122], carboxylic acids [103], dithiocarbamates [123,191], carbodithiolates [75], dithiocarboxylic acids [93], tetrathialfulvalenes [131], phosphonic acids [101,102,192] and cathecols [136] terminal groups have been assembled in SAMs and their electrical response evaluated. Some of these multidentated anchor groups have been demonstrated to exhibit superior electrical properties. For instance, dithiocarbamates on gold result in improved stable and low contact resistance junctions in comparison to thiol contacts, with a drop in the contact resistance by ca. 2 orders of magnitude [123]. Multipodal platforms also provide firm coupling between the molecule and the electrode through individual anchor points, and are also receiving increasing interest. Examples include tripodal [134,135,193] and tetrapodal [194] platforms incorporated onto SAMs which, allow to make a strong contact and to enforce an orientation of the molecules at a fixed distance from the surface [190]. Additionally, a selection of the bulky tripodal platform guaranties an effective separation with the metal surface, avoiding the quenching of the excited state caused by the metal surface in a photoisomerization process, allowing to develop optoelectronic devices of great interest in the electronic industry [82]. Construction of multilayer films using multipodal molecules by hydrogen-bond formation through $\mathrm{pH}$ control has also been used to demonstrate long-range electronic transport [192]. Other relevant properties in multipodal platforms have also been found, including attenuation of tunnel currents more effectively than do the corresponding monodentate SAMs, which may be useful in future applications for gate dielectric modification in organic thin-film devices [101]. More examples of both multidentate $[74,81,195]$ and 
multipodal [196-198] platforms have been studied at the single molecular level, though the extension of these investigations to large-area ensembles is a topic of growing interest.

The incorporation of compounds with different molecular lengths has been recently explored as a tool to tune the electronic interaction between neighbor molecules in these mixed SAMs, which results in changes in the quantum tunneling performance of the devices $[199,200]$. This result opens the door to the exploration of new functionalities taking advantage of the lateral supramolecular organization of the molecules in SAMs. Whilst, the incorporation of photochromic moieties to fabricate switching molecular electronics devices, where it is possible to control the on/off state by external stimuli, is also a topic of interest [201].

In addition to the standard SA method, the combination of SA capabilities with other techniques, such as electrochemistry results in the electrically assisted self-assembly methodology [202-207] that may result in a significant decrease in the deposition time and an improve in the quality of the monolayer.

Self-assembly strategies in which molecules are located onto a gold electrode by forming covalent $\mathrm{Au}-\mathrm{C} \sigma$-bonds [208] have resulted in SAMs with a significantly higher conductance than those with the above-described conventional anchoring groups [76,209-211]; electrically transmissive monolayers with Au-C junctions have also been reported [112]. These results are attributable to the creation of exceptionally stable SAMs $(\sim 4 \mathrm{eV})$ and strong electronic coupling because of an uninterrupted conjugation between the electrode and the molecule $[107,212]$. These investigations have been extended to other interfaces, including various metal- $C$ and $C$ (from the electrode)- $C$ (from the molecule) [212], as well as silicon-C junctions [34]. Ultrastable SAMs with high thermal, hydrolytic, chemical, oxidative, and electrochemical stabilities of N-heterocyclic carbenes (NHCs) on gold have also been demonstrated [213].

Proteins are basic elements that work as building blocks in bioelectronics devices, including protein-based transistors or sensing applications (monitoring bio-molecular interactions between target molecules and proteins). In this context, an important body of research in the field of molecular electronics is being done with proteins both at a single-molecule level [214-218] and thin-films comprising a monolayer or a short number of layers [219-223]. Additionally, it has been experimentally and theoretically proved that it is possible to tune molecular electron transfer rates in electron transfer proteins (ETpr's) through (i) chemical modifications and changes in the redox center, as well as the locations of the donor, the acceptor, and the bridge moieties within the ETpr's structure [220,224-228] (ii) modifying the solvent environment [229], and importantly, (iii) orientation relative to the electrode and changing the strength of the protein-electrode coupling [230-232]. The study of large-area protein-based molecular electronic devices has been carried out mainly by the self-assembly method $[148,149]$ via an appropriate linker. DNA has also focused the interest of researchers in the molecular electronics community due to several reasons, including (i) superior self-assembly properties [233,234]; (ii) its unique electrical properties [235], and (iii) its potential use in bioelectronics devices. Additionally, a combination of self-assembly and dielectrophoresis (DEP) methodologies has been pointed out as an efficient tool in the construction of nanodevices [236]. Relative large materials in the field of molecular electronics, including proteins, DNA, carbon nanotubes, graphene oxide, nanoparticles, etc., can be assembled onto an electrode by means of DEP $[148,223,237-243]$. DEP is based on the movement of a polarizable nanoscale object (neutral or charged) caused by the polarization of such nano-object induced by a non-uniform electric field [244-252]. Coulomb interactions between the induced surface charges of the nano-object and the electric field occur. If the nano-object is in a uniform electric field, the net force acting on the nano-object is zero. In contrast, in a non-uniform electric field, there is a net force acting on the nano-object. This net force results in the motion of the nano-object since one end of the dipole is in a weaker field than the other, and the nano-object is pulled electrostatically along the electric field gradient. There are two types of DEP: positive and negative. If the nano-object experiences a force towards the high-field intensity region, the phenomenon is known as positive dielectrophoresis. In positive DEP, the nano-object has a larger polarizability than 
the surrounding medium, and it is pushed towards the region of a higher electric field. In contrast, if the nano-object experiences a force towards the low-field intensity region, the phenomenon is called negative dielectrophoresis. In negative DEP, the nano-object has smaller polarizability than the surrounding medium. Deposition through dielectrophoresis can be experimentally controlled by adjusting a series of parameters, including the dielectric constant of the nano-object and its surrounding medium, magnitude and frequency of applied electric field, and electric field gradient.

As mentioned in the introduction, this vast body of research related to SAMs of organic, organometallic, and biomaterials may find direct use in the incorporation of molecules in large-area devices that may work as molecular wires, diodes, molecular switchers, rectifiers, single-molecule or protein-based transistors, etc. The control of the thermoelectric properties of SAMs (by using an appropriate anchor group, where the Seebeck coefficient can be boosted by more than an order of magnitude), represents a critical step towards functional ultra-thin-film devices for future molecular-scale electronics $[253,254]$. Other applications of SAMs beyond the field of molecular electronics include, just to mention a few examples, the protection of electrodes from otherwise highly detrimental environments preventing electrochemical corrosion. This is a useful finding to increase, for instance, the lifetime of electrochromic devices [102]. Moreover, nanotemplating (which resembles the host-guest interaction in supramolecular chemistry) can be applied in molecular separation, chemical sensors and nanoreactors [255]. This technique has been also used as a tool to fabricate hybrid organic/inorganic nanostructures with application in sub-5 $\mathrm{nm}$ bottom-up patterning nanolithographic processes, which is an important point for the development of future electronic devices [256]. Other research fields where SA appears as a useful and versatile working technique include the development of drug delivery systems [257,258], the merge of advanced nanomaterials and optical fibers, known as lab-on-fiber optrodes [259], as well as biopharmaceutical applications [260], among many others.

\subsection{The Langmuir-Blodgett Technique}

In contrast to the SA method, in which molecules are first assembled onto the substrate, and subsequently, they are organized, in the Langmuir-Blodgett method, molecules (amphiphilic in nature) are first organized at the air-liquid interface (the liquid is usually water). The driving forces operating for the arrangement of the molecules at the air-liquid interface are mainly van der Waals interactions, hydrogen bonding, and/or electrostatic interactions. In addition, the $\mathrm{pH}$ of the liquid subphase, as well as the presence of ions can also govern the organization of the molecules [261]. Once the monolayer at the air-water interface, Langmuir film, is well-formed, it can be transferred onto a solid substrate to fabricate a Langmuir-Blodgett (LB) film. The transference can be done either by the emersion or the immersion of a vertical substrate (electrode) with respect to the air-water interface or by the horizontal lifting of a substrate located parallel to the subphase (Langmuir-Schaefer, LS, methodology). Depending on the nature of the solid substrate and the anchor groups present in the molecules, the molecules can be physisorbed or chemisorbed [126]. The main advantages associated with the Langmuir-Blodgett technique include:

- Fabrication of high-quality monolayers with high internal order;

- Fabrication of homo and heterogeneous multi-layered systems [262], resulting in highly ordered 3D molecular architectures;

- Fabrication of directionally oriented monolayers when asymmetric molecules are used [37,114].

- Large control of the orientation and the packing density of the molecules within the LB monolayers through optimization of different parameters that can be modified upon the manufacturing process, including the nature of the subphase, the spreading solvent (or even mixture of solvents), the temperature, the closing barriers speed, the dipping speed, the transference pressure, or transference direction of the electrode; 
- In situ characterization of the Langmuir film upon the compression process by a wide variety of techniques [263-270] as surface pressure vs. area per molecule and surface potential vs. area per molecule isotherms, Brewster Angle Microscopy (BAM), ellipsometry, X-ray reflectometry, dilational rheology, Infrared reflection spectroscopy or UV-vis reflection spectroscopy, etc. These techniques provide complementary information for the understanding of the intermolecular interactions in the film;

- A really large number of different anchor groups can be used in the LB methodology in contrast with the SA method since these groups can be not only chemisorbed but also physisorbed onto the electrode. Furthermore, the transference of these films is possible to almost all types of substrates (e.g., metals, conducting polymers, silicon, carbon-and graphene-based electrodes, etc.).

The historical background and comprehensive descriptions of the technique have been reported before $[90,91,261,271,272]$. The Langmuir-Blodgett technique, illustrated in Figure 3, involves a more complex monolayer formation process compared to the SA method. Briefly, a Langmuir though is used. The basic elements of a Langmuir though include a cuvette made of a hydrophobic material, one or two barriers, and a Wilhelmy plate to determine the surface pressure (defined as the difference between the surface tension of pure water minus the surface tension of the water with the monolayer). Additionally, the transference of the monolayer onto the substrate requires a dipper to introduce or withdraw the substrate. The starting point in the LB process is the spreading of a solution of the molecule in an organic solvent. The solvent must dissolve the material, be highly volatile, and exhibit a large spreading coefficient. A certain volume of this solution is carefully spread onto the subphase. After waiting for the solvent evaporation, the compression process starts with the aid of one or two mechanical barriers, and the surface pressure vs. area per molecule is recorded. Therefore, as the available area per molecule is being reduced, the molecules get closer resulting in intermolecular interactions. This gradual change in a molecular arrangement is reflected in surface pressure variations registered with the Wilhelmy balance. Thus, upon the compression process, the monolayer undergoes several bi-dimensional phases (gas, liquid expanded, liquid condensed, and solid) and phase transitions. Once the monolayer reaches the target surface pressure of transference, the Langmuir film can be deposited onto a solid substrate, forming an LB monolayer (LBM).

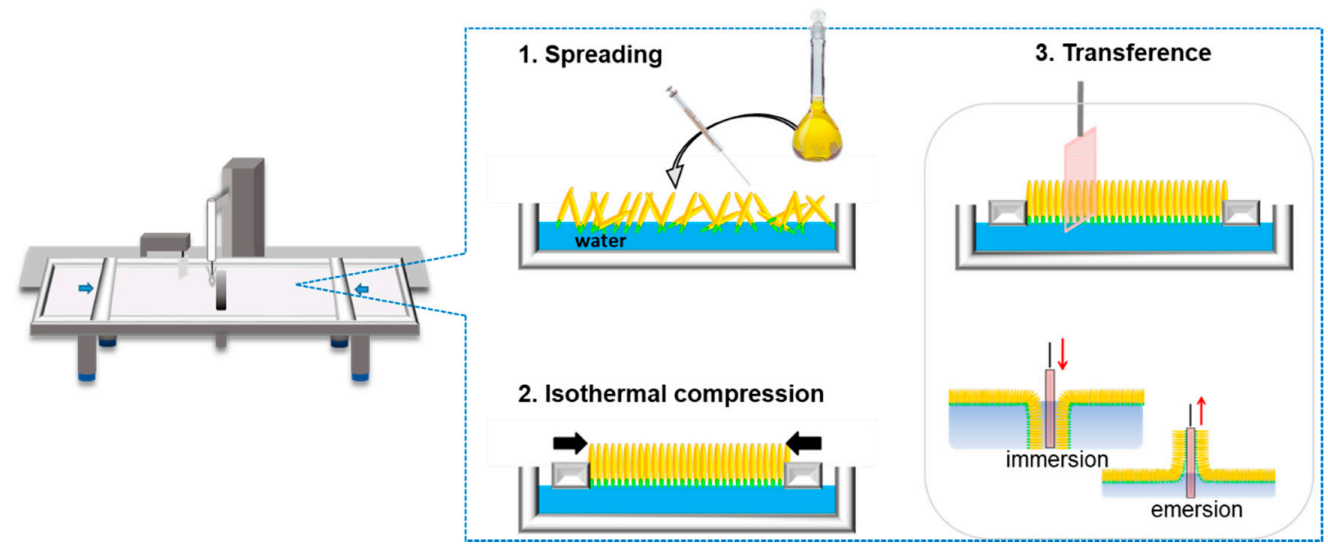

Figure 3. Scheme showing the main steps involved in the Langmuir-Blodgett monolayer (LBM) fabrication. First, an organic solution containing the molecule of interest is spread on the water surface. Second, the molecules are organized upon an isothermal compression resulting in a Langmuir film. Finally, the monolayer is transferred onto a solid support-forming the LBM.

Possibly the main drawback of the LB method is that it is a time-consuming technique. Concerning the fabrication process, a slow and critical step is the manual spreading process. Here, the electrospray (ES) spreading methodology could be an alternative to make this technique more functional and likewise to improve reproducibility. For instance, this methodology has been recently 
employed by Hirahara et al. [273] to obtain LBMs incorporating clay mineral nanosheets hybridized with the $\mathrm{ODAH}^{+}$, where a comprehensive analysis of the influence of the infusion rates on the film properties is carried out.

In general terms, the materials typically used for the fabrication of LBMs are water-insoluble molecules with a head (hydrophilic)-tail (hydrophobic) amphiphilic structure [90,262,271,274]. Molecular assemblies using the LB technique for fabricating large-area molecular electronic devices of highly conjugated materials with monodentated anchor groups, such as thiols [114,275], nitriles [79], amines [21,276], trimethylsilylethynyl group [113,277], acetylenes [120], pyridines [125,278], or a viologen moiety [83], have been constructed. Additionally, the use of multidentate or multipodal anchor structures to improve the robustness and stability of the molecular junction has also been explored. For instance, using acids [116,118,279] or diacids [37], methyl esters [121], tetrathiofulvalenes [280], a 2-aminopyridine group [127], a pyrazole moiety [81], or the tripodal head group 2,6-bis((methylthio)methyl)pyridine [126].

Conductance in large-area molecular electronic devices incorporating carboxylic groups with lateral intermolecular H-bonding can be enhanced by deprotonation in a basic media with the subsequent rupture of those $\mathrm{H}$-bonds. Therefore, this demonstration exploits the switching behavior in the conductance under protonation-deprotonation conditions for the construction of $\mathrm{pH}$ sensors based on molecular junctions [37]. Moreover, an LB film of a dyad consisting of an electron-rich " $\pi$-donor" (D) and an electron-poor " $\pi$-acceptor" (A) separated by a rigid, insulating "spacer" (featuring three main components of the original Aviram-Ratner rectifier design) has shown rectification behavior validating the rectification proposal by Aviram, and thus, allowing the possibility of producing organic molecular rectifiers [280].

In addition to the typical amphiphilic molecules described above, the LB technique is largely enlarged towards the assembly of more complex structures with interest in molecular electronics (and organic electronics). Polymers [281-283], metalloporphyrines [284], DNA [285], perylenes [286], perylene- $\mathrm{NH}_{2}$ [287], ruthenium complexes [288], organo-modified inorganic nanoparticles in combination with polymer nanospheres (nano-mille-feuille system) [289], pillar[5]arene derivatives [290], polymer-coated $\mathrm{CsPbBr}_{3}$ nanowires [291], aligned SWCNTs [145], semi-conductive 2D materials based on 2,3,6,7,10,11-hexaiminotriphenylene (HATP) [292], or rGO [146] have been used.

Although this review is focused on the potential of this bottom-up technique in the construction of monolayers with applications in molecular electronics, the LB technique has been applied in many other research fields. Here, it is worth mentioning the role of the LB methodology in many other fields of research that cover a large in the emerging concept nanoarchitectonics [293,294], which combines nanotechnology with other fields, such as supramolecular chemistry, nano/micro fabrication, organic chemistry, and bio-related technology. Nanoarchitectonics represents today a promising and powerful strategy in which the LB method yields a perfectly molecular organization within a 2D plane [295,296]. Therefore, because of the wide generality of the nanoarchitectonics concept, LB films can also be applied to a wide range of research fields with practical importance, such as materials production [297-299], sensing [300,301], catalysis [302,303], device [304,305], energy [306-310], or biological/biomedical applications [311-314], or even in the fabrication of smart textile-based sensors (TEX sensors) [311]. These studies underscore the almost limitless possibilities of the LB technique to fabricate well-ordered 2D films of a wide range of materials.

\subsection{The Electrografting Technique}

Electrografting (EG) is a well-known approach for surface functionalization or modification, in which an electrochemical reaction takes place between the conductive substrate and organic material [312]. This methodology has two main and powerful advantages:

- The formation of a direct covalent bond between the electrically active molecule (s) and the electrode, resulting in stable and robust molecular junctions. 
- Carbonaceous electrodes (in addition to other conductive substrates, such as metals, metal oxides, polymers, and semiconductors) are relatively easy to functionalize. The use of carbon-based electrodes represents a growing trend today in the development of sustainable technology able to manufacture electronic devices free of expensive and contaminant materials [313].

Nevertheless, the main drawback associated with this methodology is the tendency to form non-ordered multi-layered systems, due to the extremely high reactivity of free-radicals involved in the electrografting process. Several strategies have been successfully used in order to avoid such a multilayer growing. These approaches include molecular functionalization with bulky groups or the use of redox mediators or inhibitors [314,315].

EG covers reductive and oxidative processes, depending on the organic compound, as was comprehensively described before by Bélanger and Pinson [312]. Since this methodology was developed [316], different functional groups have been used for surface modification, including aliphatic amines [99], aromatic amines [317], or diazonium salts [314,315].

In the field of molecular electronics, widespread research concerns the modification of a bottom electrode (metals, carbon-based electrodes, hydrogenated silicon surfaces, etc.) by electrografting of diazonium salt derivatives [314,315,318,319]. One of the preferred methodologies to generate diazonium cations is the in situ diazotization of aromatic amines, as illustrated in Figure 4 [320]. As a general procedure, the diazotization step is followed by the electrochemical reduction, where highly active aryl radicals are produced. Subsequently, these radical intermediates covalently bind to the surface [128].

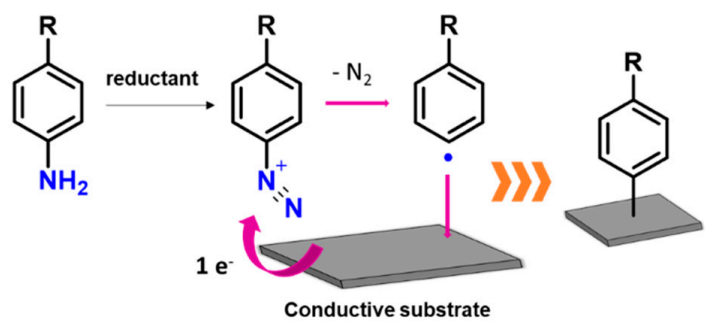

Figure 4. Scheme showing the electrografting process for a diazonium salt.

Numerous examples can be found in the literature reporting molecular electronic devices based on the electrografting of diazonium salts. Here, it is noteworthy the pioneering work done in the group of McCreery [321,322], that reported the first all-carbon based molecular tunnel junctions. This group also developed methodologies for the grafting of diazonium salts onto a pyrolyzed photoresist film (PPF) [323] and has recently reported an all-carbon molecular electronic device constructed on flexible or semi-transparent substrates [33]. These methodologies and materials pave the way for applications in which molecular electronics and photonics are combined. Additionally, the McCreery group also launched the first commercialized molecular electronic device, in which a molecular rectifier composed of a molecular layer sandwiched between two carbon-based electrodes is used for audio processing applications [72].

A different and emerging family of suitable molecules for indirect or direct electrografting are iodonium salts [130]. Concerning the direct grafting, Guselnikova et al. [324] have reported the surface functionalization of a gold substrate by UV-light grafting of the 3,5-bis (trifluoromethyl)phenyl)iodonium salt. Ramírez-Chan et al. [325] recently described the fabrication of electrografted films by oxidation of a nitrophenylbutyrate derivative $\left(\mathrm{NO}_{2} \mathrm{Ph}\left(\mathrm{CH}_{2}\right)_{3} \mathrm{COO}^{-}\right)$exploring the influence of different supporting electrolyte ions on the film formation. Madsen et al. [326] used a two-phase bipolar grafting system to simultaneously functionalize gold bipolar electrodes with diazonium salts and primary amines or thiophenes.

In addition to the fabrication of exceptionally robust monolayers for molecular electronics applications, this technique is an affordable methodology to reach specific improvements in surface 
functionalization for an extensive variety of substrates. For example, mixed monolayers made of organophosphonic derivatives have been electrografted onto nitinol (NiTi), which is an alloy often employed in the biomedical field, in order to prevent the release of the possibly carcinogenic $\mathrm{Ni}^{2+}$ ions [327]. Kim et al. [143] modified a GLAD-ITO substrate by the electrografting of a porphyrin diazonium salt, showing the possibility to introduce molecular functionalities, such as photo-activity on nanostructured metal oxides electrodes. Moreover, polymers, such as the PEDOT (Poly(ethylenedioxythiophene) films, have been electrografted to repair IMPC (Ionic exchange polymer metal composite) to overcome the problem of water leakage and also providing reinforced properties to the electrode [328]. Another approach to enhance the adhesion of PEDOT onto ITO and gold surfaces was presented by Villemin et al. [329], who introduced a two-step strategy in which the first step consists of the fabrication of an electrografted promoter layer based on EDOT or thiophene moieties. Likewise, materials, such as carbon nanodots (CD) have been immobilized onto carbon substrates, through the attachment of nitrogen moieties at the nanodot surface (diazotized N-CD), resulting in carbon substrates with new performances in sensing applications [330]. Finally, other conductive substrates such as carbon composite electrodes, including thermoplastic electrodes (TPE) [331], edge plane pyrolytic graphite electrodes (PGEs) [332], glassy carbon (GC), and pyrolyzed photoresist (PPF) [333], have also been modified by electrografting.

Finally, two useful and recent advances in this field are worth mentioning. One of them results from the merge of the LB and the electrografting techniques and was recently published by Gabaji et al. [334]. In this methodology, the electrografting process occurs simultaneously to the transference of the Langmuir film onto the solid substrate. The other relevant approach results from the combination of EG with the electrode mediated shadow edge deposition methodology; here, molecules of 9,10-dioxo-1-anthracenediazonium salt were covalently attached to metallic nanotrenches producing stable and reproducible lateral architectures of molecular junctions [335].

Although EG is widely utilized for the construction of monolayers with applications in molecular electronics, this technique is also used in many other research fields as well as in industrial applications. In this context, it is worth mentioning the development of a diazonium-based biochip for surface plasmon resonance (SPR) analysis, a well-established technique for studying affinity between biomolecules whose interaction takes place in a liquid/solid interface [336], by electrografting of a carboxybenzene diazonium salt [337]. Additionally, electrografting, followed by a post-functionalization, is being an interesting approach in the design of well-defined interfaces for electrochemical (bio) sensing, very important in fields, such as chemistry, materials science, engineering, biology or medicine [320]. Furthermore, EG is an important tool to modify electrodes in bipolar electrochemistry applications, which involves two feeder electrodes and a conducting object (the bipolar electrode) in an electrolytic solution; a field of renewed interest in the last decades, due to its use in materials science or sensing [338]. Accordingly, EG can be applied in a wide range of applications in the areas of catalysis, biosensors, sensors, corrosion protection, composite materials, energy conversion, energy store, or superhydrophobic coatings, which reveals the enormous possibilities of the EG methodology to fabricate bi-dimensional arrangements using a wide range of materials. EG is also used in industrial applications, such as the modification of carbon black by simple mixing with diazonium salts generated in situ in aqueous solution (patented by Cabot Coorporation, Boston, MA, USA) to produce pigments for inkjet applications, automotive coatings, solar cells, and fuel cells [339]; or the fabrication of drug-eluting stents (endovascular devices to deliver locally therapeutic agents) [340]; revealing that EG technique is as a powerful tool for real-life applications.

To sum up, in this section, the most relevant techniques for the construction of monolayers onto (semi-)conducting or dielectric surfaces for molecular electronic applications have been covered, with examples of a large variety of technological applications. Table 2 gathers the main concepts here presented and may serve as a comparison scheme with the different pros and cons of each of these methodologies. 
Table 2. Comparison of the deposition techniques to fabricate molecular films.

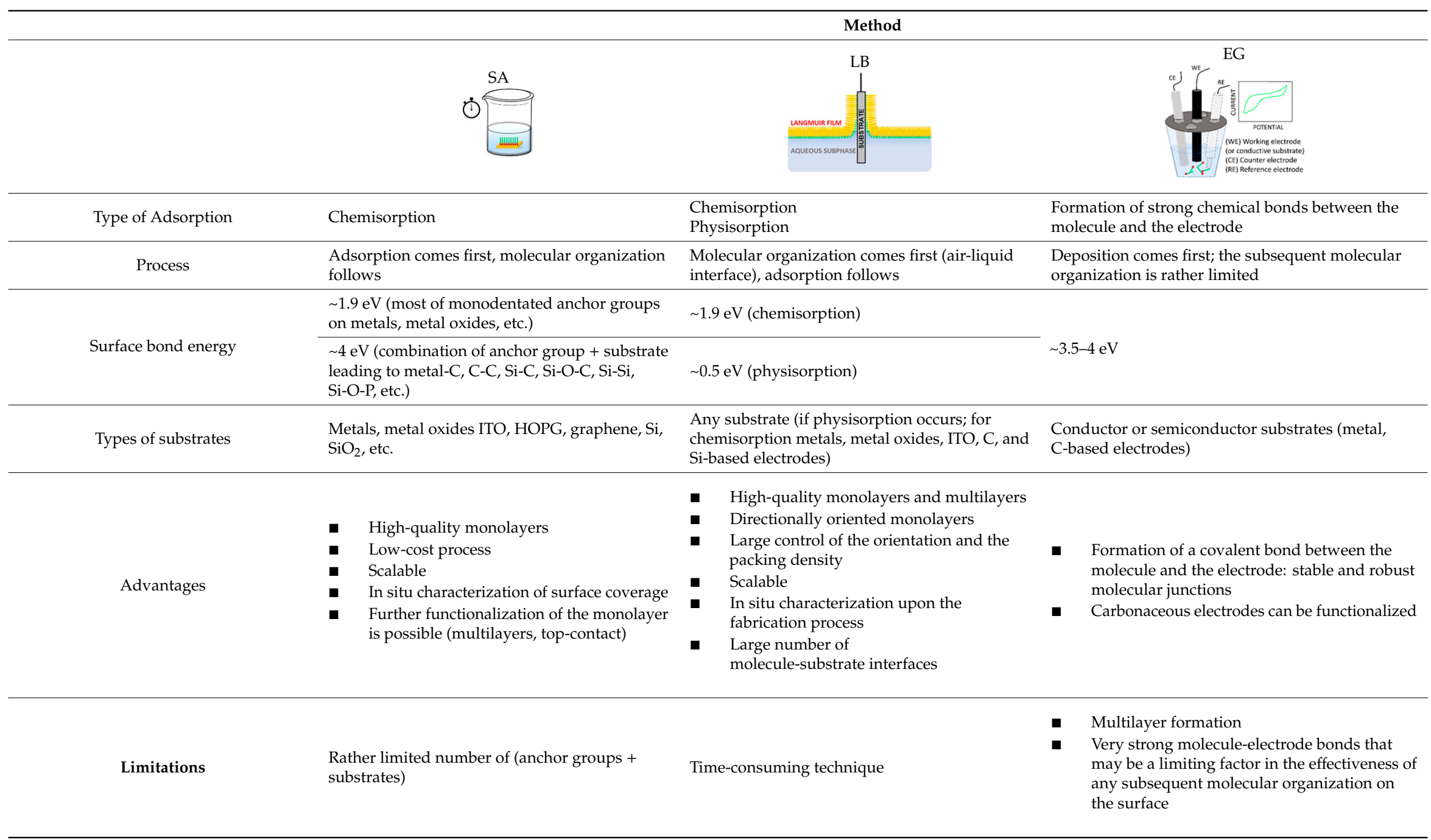




\section{Fabrication of the Top Contact Electrode}

Once the molecules have been assembled using some of the methodologies above-described onto a bottom-electrode, the subsequent deposition of a top-contact electrode to close the circuit is one of the most crucial and delicate steps in molecular electronics. Even when the deposition of the top-contact electrode has been largely investigated, having a reliable control in the fabrication of this electrode is still a challenge to reach viable incorporation of molecular electronics in the market. Different techniques have been employed to deposit or make a top-contact electrode, including physical or chemical vapor deposition, atomic layer deposition, liquid metal droplets, break junctions, scanning probe tips, electrodeposition, electroless deposition, etc. Moreover, these techniques can be divided into two categories: (i) Those that can be used to integrate molecular constructs into devices; and (ii) those that are employed for characterizing molecular electronic properties. In this review, we will focus mainly on the first ones. Moreover, the reader can find elsewhere excellent and comprehensive reviews that describe in detail the methods used to characterize, in the laboratory, molecular electronic properties through the formation of temporal metal-molecule contacts, but that are unsuitable for large-scale integration such as: In situ break junction (STM-BJ), mechanically controlled break junction $(\mathrm{MCBJ}), I(s)(I=$ current, $s=$ distance $)$ and $I(t)(I=$ current and $t=$ time $)$ methods based on an STM, electromigration breakdown junction, liquid metal droplets, etc. $[9,84,169,341]$. In the MCBJ, firstly, a fine metal bridge is formed, and subsequently, this is cleaved upon bending the whole assembly allowing forming the molecular bridge. Similarly, in the STM-BJ method, break junctions are mechanically formed using an STM tip to create a metallic contact to the substrate, which is then cleaved, forming the molecular bridge, while monitoring the current. On the contrary, in the $I(s)$ method, although it also uses an STM tip to form molecular junctions, there is no contact between the metal electrodes since the STM tip is brought close to the surface and then withdrawn, while the tunneling current is measured. Meanwhile, in the $I(t)$ method, the STM tip is placed at a constant distance from the substrate, and the formation of molecular wires is monitored in the time domain.

Top-contact electrodes on molecular assemblies have been fabricated by direct evaporation of metals using either physical vapor deposition (PVD) [342] or chemical vapor deposition (CVD) [343]. In PVD, the top-electrode is formed by evaporating a metal, at a sufficiently high temperature and low pressure, for the subsequent condensation of metal atoms in the molecular layer. Nevertheless, in this method, both the film thickness and the spatially selective growth of the metallic film are difficult to control. CVD is a more selective technique and permits higher control in the thickness of the metal deposition than PVD. However, CVD is characterized by rather slow growth rates unless high thermal activation temperatures $\left(\geq 20{ }^{\circ} \mathrm{C}\right)$ are employed, with these high temperatures being incompatible with most organic thin-films. Regardless if PVD or CVD are used, both methods often result in damage to the monolayer and also in penetration of metal atoms through the monolayer, and therefore, metallic contact between the top and bottom-electrodes [84,344,345]. Alternatives (such as metal evaporation onto a cooled substrate [346,347], blocking the direct path between the crucible and the sample with baffles [348], or the use of an indirect evaporation method to reduce the exposure of the molecular layer to energetic metallic atoms and temperatures [349]) have been proposed to minimize damage to the monolayer, as well as the presence of short-circuits.

The incubation of a functionalized monolayer into a metal nanoparticle dispersion results in the chemical deposition of the metal nanoparticles on top of the organic layer. In this context, gold nanoparticles and thiol functional groups have been widely used [350]. However, this methodology results in an incomplete metallization of the organic layer [350]. Therefore, alternatives to increase the surface coverage of the metal deposits have been developed. For instance, the photoreduction by UV-vis light of a metal precursor provides surface coverage of the monolayer surface as large as $76 \%[115,277]$. In this methodology, the metal precursor is incorporated from an aqueous subphase to an LBM upon the transference process, generating in situ metal nanoislands on top of the monolayer by photoreduction of the precursor. This method has been proved not to damage the underlying organic film, nor penetration of the nanoparticles through the film Additionally, anisotropic palladium 
nanostructures, previously produced by a CO-confined growth method [351,352], were deposited onto the monolayer to generate large palladium nanodeposits (PdND) across the surface without any damage to the monolayer, and importantly, a surface coverage of $85 \%$ [111]. Moreover, the incorporation of in situ generated uncapped gold nanoparticles (NPs) has been explored. Here, the NPs were attached to a terminal alkyne functionalized monolayer through the formation of $\mathrm{Au}-\mathrm{C} \sigma$-bonds, via a heterolytic cleavage of the alkyne $\mathrm{C}-\mathrm{H}$ bond [107].

An interesting methodology for the soft deposition of metallic contacts such as $\mathrm{Au}, \mathrm{Pt}$ and $\mathrm{Cu}$ with yield $>90 \%$ is the surface-diffusion-mediated deposition (SDMD) [353,354]. In this approach, firstly, a $\mathrm{SiO}_{2}$ etch mask patterned on a pyrolyzed photoresist film (PPF) layer, is fabricated by optical lithography on a silicon substrate with a thermal $\mathrm{SiO}_{2}$ insulating layer. After that, the molecular layer is formed on the conducting PPF substrate through a $\mathrm{C}-\mathrm{C}$ bond by electrografting. In order to protect the monolayer from the source radiation or from the direct impingement of metallic vapor generated by using electron-beam evaporation, an adjacent silicon dioxide layer is used. Surface diffusion of the metal atoms from the silicon dioxide to the molecular layer leads to the formation of a "soft" top contact, albeit this approach has a significant addressability problem.

Atomic layer deposition (ALD) is a chemical process related to CVD but differs from it in several key aspects [355-357]. ALD involves a well-defined chemical reaction route to form the top-contact. In this methodology, the related chemical reactants (or precursors) are sequentially introduced into the reaction chamber via short pulses (each of them followed with a purge of inert gas to remove excess reactants). A layer-by-layer deposition onto the organic film takes place. Here, the free-ends of the molecule have been specially designed to exhibit affinity by these chemical reactants (or precursors) favoring a selective reaction. Since the film growth is self-limiting, atomic-scale control of the film thickness and minimization of the defects (pinhole-free films) is achieved. Subsequently, this protective molecular layer can be used to deposit a thicker metal film using traditional methods. ALD is very advantageous in fabricating metal-insulator-metal tunnel junctions (MIMTJ) and provides a high control of the thickness of the ultrathin insulating layer inserted in the junction [356]. For these reasons, ALD is considered an enabling technology for future electronics. In addition, based on this methodology, the conductor polymer PEDOT:PSS (where PSS is poly(4-styrenesulphonic acid)) has been used as an interlayer in large-area molecular junctions resulting in very stable devices with a shelf life of more than several months. The main drawback of this methodology may be associated with the presence of hydrophobic end groups in the monolayer that can difficult the subsequent deposition of the hydrophilic PEDOT:PSS [358].

Electrodeposition could be an attractive method for the metallization of monolayers because it does not require expensive vacuum equipment, and it is often easier to control. However, this methodology has so far been unsuccessful since the formation of clusters, or the penetration of metal ions from the solution or even metal wires through the defect sites in the monolayer are often observed-resulting in very low yield devices $[84,359,360]$. Although these problems-which are mainly associated with the existence of imperfections in the monolayer and the presence of free metal ions in the solution-have been able to be overcome or reduced [22,361-363], still exits serious limitations in this approach. Only $1 / 3$ of the monolayer is covered by the top metal layer; albeit this value can be increased until an almost completely covered SAM by repeating the adsorption-electrochemical reduction cycle in a metal ion free solution, but with the inconvenience of increasing the presence of short-circuits $[364,365]$.

An alternative to reduce or eliminate the inconvenient of metal penetration is electroless deposition. This approach allows the deposition of metals and other materials on a variety of substrates $[84,366]$. It is very similar to electrodeposition in the sense that the metal deposition results from the reduction of metal ions from solution, but without applying an external potential, which additionally makes this method compatible with insulating or low conductivity materials. However, electroless deposition often requires the use of a catalyst to be adsorbed on the surface prior to the metal deposition, which can contaminate the organic layer affecting the final functionality of the junction [367-369]. To control the diffusion of the catalyst, the organic layer can be functionalized to selectively adsorb the catalyst, 
limiting the metallization to the functionalized areas [370,371]. A modification of this method is the electroless nanowire deposition on micropatterned substrates, which is employed to direct the growth of metallic nanowires on the monolayer surface [368].

To solve the problems that arise from damage to the monolayer or formation of short-circuits, different non-destructive methods have been developed. Nanotransfer printing (nTP) is one of these methods that fabricate soft top-contact electrodes by transferring the metal contact to the monolayer (by mechanical contact) from elastomeric poly(dimethylsiloxane) (PDMS) or perfluoropolyether (PFPE) stamps [372,373]. The transference is a consequence of the chemical affinity between the metal contact and the anchoring groups present in the monolayer, for instance, a thiol-terminated monolayer and a gold metal contact [374]. By using the lift-off float-on (LOFO) method [374], a metal film can be transferred onto a monolayer via capillary interactions avoiding the physical damage in the monolayer. This approach includes basically four steps: (i) Evaporation of a metal film onto a solid support (denoted as leaf); (ii) detachment of the metal leaf from the solid support by floating the leaf at the liquid surface (lift-off); (iii) adsorption of a monolayer onto a solid support; and (iv) attachment of the metal film at the liquid surface to the monolayer supported in the solid substrate using a liquid-mediated process (float-on). Several different types of molecular junctions without any observable damage to the monolayer have been formed using this method [9]; however, the wrinkling of the leaf, the presence of air gaps between the monolayer and the leaf, as well as small monolayer-metal contact areas limit LOFO methodology for further applications and mass production. The transfer of a top metal layer with a hydrophobic polymer, polymer-assisted lift-off (PALO, which combines aspects of nTP with LOFO), solves the wrinkling problem and the small metal contact area in LOFO. Using PALO, metal electrodes with dimensions from $100 \mu \mathrm{m}^{2}$ to $9 \mathrm{~mm}^{2}$ can be produced with high yield ( $\geq 90 \%$ ) [375]. In this methodology, the alignment of the top and bottom contacts without using cross-bar geometries is a significant difficulty.

Other relevant methods for fabricating molecular junctions are via the construction of a hole, such as a nanopore or a nanowell [375-377]. To fabricate a nanopore device, a thin $\mathrm{Si}_{3} \mathrm{~N}_{4}$ layer is deposited in a double-sided polished silicon wafer. A window, suspended over the silicon wafer, is obtained by optical lithography, reactive ion etching (RIE), and wet etching techniques. After that, a gold layer is evaporated onto the top side of the membrane, filling the pore (the top electrode). Then, the sample is immediately incubated in a solution to assemble a molecular layer on the top electrode surface. Finally, the sample is placed in a vacuum chamber to thermally deposit the bottom metal $(\mathrm{Au})$ electrode. Recently, large-area junctions based on SAMs deposited in $\mathrm{AlO}_{\mathrm{x}}$ micropores fabricated on ultraflat template stripped bottom electrodes of gold $\left(\mathrm{Au}^{\mathrm{TS}}\right)$ have been fabricated with high mechanical stability [378]. The construction of a nanowell is more simplified, and occurs in a planar device in contrast with the nanopore. In this case, a nanowell device is fabricated on silicon wafers incorporating pre-patterned gold electrodes covered with silicon dioxide prepared with the focus ion beam (FIB) technique. After the hole is created, molecules are self-assembled on this bottom electrode, and the hole is filled with gold to close the circuit. The disadvantages of these approaches are: The requirement of delicate processes during the sample fabrication, the non-reproducible electrical properties from sample to sample, and a higher ratio of short-circuits by penetration of the metal, overall in nanopore devices. However, to overcome these disadvantages, a conducting buffer interlayer can be inserted between the metal layer and the monolayer to avoid damaging the organic layer, which allows the creation of large-area molecular junctions [358,379-386]. Another alternative to fabricate large-area junctions is to create microfluidic channels made with an elastomeric polymer (PDMS) on the bottom electrode using conventional photolithography in which the organic layer is self-assembled, and then the channels are filled with $\mathrm{Ga}_{2} \mathrm{O}_{3} / \mathrm{EGaIn}$ electrodes [387]. It is noteworthy that even when large contact areas can be fabricated by LOFO, PALO, nano (micro) pore, or nanowell and microfluidic channels approaches, these techniques are not easily scaled up for the fabrication of molecular electronic devices; in contrast, nanotransfer printing approaches represent a promising methodology to fabricate integrated molecular devices. 
Other radical different alternatives to fabricate "soft" top-contact electrodes have been developed recently. Examples include the so-called Thermal Induced Decomposition of an Organometallic Compound (TIDOC) method in which an organometallic film is thermally decomposed-resulting in the formation in situ of gold nanoislands on top of the film without producing short-circuits by penetration of the metal top-contact electrode through the layer [137,138]. Moreover, the fabrication of nanotrenches of controlled width by means of the shadow edge evaporation method resulting in molecular junctions with very good stability and reproducibility, which offer the advantages of large scale integration, reduced leakage currents, and easier access to the molecular layer with external tools [335]. Additionally, the DEP method (described before in this review) has also been used for the controlled deposition of a top contact electrode. Fereiro et al. used Au nanowires electrostatically trapped between two microelectrodes. The Au nanowire act as the top-contact electrode in a flat gold | protein monolayer | Au nanowire junction [148].

While the ordinary metal electrode molecular junctions described above remain operational, experimental platforms based on non-metal materials are being constructed, leading to new possibilities for molecular-scale electronics. Carbon electrode-molecule junctions are one of these new testing systems, where several carbon materials, such as reduced graphene oxide (rGO), graphene, or single-walled carbon nanotubes (SWNTs) are used as top-contact electrodes because of their unique advantages [9]. Graphene or rGO films fabricated by chemical vapor deposition have been widely used as the conductive interlayers in molecular junctions [379,384]. Meanwhile, soft top-contacts for the non-destructive fabrication of molecular junctions using floating-processed ultrathin graphene films [384], or transferred onto the layer via poly(methyl methacrylate) (PMMA)-mediated transfer [388], have also been implemented.

Nanoscale gaps in SWNTs with precise control are fabricated by lithography-defined oxidative cutting [389], resulting in SWNT-molecule single-molecule junctions, which could be easily extended to industrial mass production since all of the operations in the process are compatible with conventional micro- and nanofabrication techniques [9]. Meanwhile, using dash-line lithography [390], robust single-molecule junctions with a high yield, based on indented graphene point electrodes can be created. This methodology provides a large control regarding the size of the nanogaps through the regulation of the etching process.

Electron beam evaporation of carbon (e-C) to create soft top-contact electrodes onto monolayers has been used successfully with a high yield, excellent reproducibility, and thermal stability [33,321,391-393]. The fabrication of amorphous carbon top-contact electrodes (with well-defined shape, thickness, and precise positioning on the film) from a naphthalene precursor using a focused electron beam induced deposition (FEBID) technique has been recently employed to create molecular junctions with a high yield and stability [117].

Once the top-contact electrode is fabricated to close the circuit, the typical way to verify that these molecular junctions, created with a given structure, are reliable is to statistically investigate the electrical characteristics of these devices. Conducting-atomic force microscope (C-AFM) and scanning tunneling microscope (STM) are the techniques usually used to address the electron transport properties of these devices by registering current-voltage $(I-V)$ curves (or density current-voltage $(J-V)$ curves). A detailed analysis of these curves together with temperature-varying measurements allow to rule out the presence of short circuits; also to determine conductance through the fabricated molecular junctions, as well as establish the mechanisms that govern the charge transport; in addition, it is possible to elucidate energy level alignments through a spectroscopic analysis (by the transition voltage spectroscopy, TVS, method). Theoretical models are also employed to better understand the charge transport mechanisms through the molecular junctions. Whilst, the shape of the obtained conductance histograms for the molecular junctions is an efficient technique to determine the interaction energy between adjacent molecules, one of the key parameters to understand and optimize the performances of these large-area molecular electronic devices. Additionally, inelastic electron tunneling spectroscopy (IETS) can be utilized to investigate the vibrational modes in the molecular junctions. In addition, 
the thermoelectricity of the molecular junction, which measures the induced voltage drop or the induced current across the junctions between two electrodes at different temperatures, helps our understanding of the mechanism of the thermoelectric effect, and therefore, may serve to improve the technologies for converting wasted heat into useful electrical energy. Finally, the determination of durability and operational stability of the device is crucial for the practical application of these devices in the actual industry.

\section{Summary and Outlook}

The use of molecules in electronic devices as critical functional elements in circuitry is expected to result in a novel technology opening the path to future industrial processes for high-value products. The use of functional organic materials has attracted a great deal of attention due to the numerous and very appealing advantages of using molecules as functional units. Importantly, the use of molecules in electronic devices is expected to result not only in the further miniaturization of transistors, but also in diminished power consumption and new functionalities, due to the quantum effects that govern the properties at the nanoscale. Researchers are currently immersed in the exploration of two different paradigms. On the one hand, the study of single-molecule junctions, which is of primary importance to understand charge transport through molecules. On the other hand, the fabrication and characterization of large-area devices in which assemblies of molecules are located between two (or three) electrodes. The fabrication of these electrode | monolayer | electrode systems can be done through simple, soft and scalable technologies that result in high-quality and reproducible monolayers, making possible the manufacture of thousands of devices. Many advances towards the deposition of a continuous top-contact electrode, without short-circuiting or damaging the monolayer, have also been made in the last years. This potential processability and scalability in the fabrication of large-area molecular electronic devices pave the way towards industrial mass production. In this review, progress in the fabrication of large-area molecular electronic devices in recent years has been presented, with particular emphasis on the techniques used for the fabrication of well-ordered and tightly-packed monolayers, as well as top-contact deposition methodologies. An overview of the current nanofabrication techniques clearly evidences that there is still a long way to go before having a well-defined manufacturing route to get integrated, high yield, robust, stable, scalable, and reproducible molecular devices, produced at a reasonable cost. A multidisciplinary approach with the collaboration of chemists, physicists, and engineers is being made in research groups all over the world to overcome these difficulties and put in the hands of the next generation an emerging technology that is expected to improve people's quality of life.

Funding: This research was funded by Ministerio de Economía y Competitividad from Spain and fondos FEDER in the framework of projects MAT2016-78257-R and PID2019-105881RB-I00. L.H., S.M. and P.C. also acknowledge projects LMP33-18 and E31_20R (Platon research group) funded by Gobierno de Aragón/Fondos FEDER (construyendo Europa desde Aragón).

Conflicts of Interest: The authors declare no conflict of interest.

\section{References}

1. Available online: https://www.360marketupdates.com/global-electronic-components-market-14830923 (accessed on 14 August 2020).

2. Lu, W.; Lee, Y.; Murdzek, J.; Gertsch, J.; Vardi, A.; Kong, L.; George, S.; del Alamo, J. First Transistor Demonstration of Thermal Atomic Layer Etching: InGaAs FinFETs with Sub-5 Nm Fin-Width Featuring in Situ ALE-ALD. In Proceedings of the IEEE International Electron Devices Meeting (IEDM), San Francisco, CA, USA, 1-5 December 2018.

3. Waldrop, B.Y.M.M.; Law, O.F.M.S.; Interesting, M. More Than Will Soon Abandon Its Pursuit. Nature 2016, $530,145$.

4. Available online: https://www.economist.com/technology-quarterly/2016-03-12/after-moores-law (accessed on 14 August 2020). 
5. D'Agosta, R.; Sai, N.; Di Ventra, M. Local Electron Heating in Nanoscale Conductors. Nano Lett. 2006, 6, 2935-2938. [CrossRef] [PubMed]

6. Available online: https://www.itrs2.net/ (accessed on 12 August 2020).

7. Available online: https://irds.ieee.org/ (accessed on 12 August 2020).

8. Arden, W.; Brillouët, M.; Cogez, P.; Graef, M.; Huizing, B.; Mahnkopf, R. “More-than-Moore” White Paper. Available online: http://www.itrs2.net/uploads/4/9/7/7/49775221/irc-itrs-mtm-v2_3.pdf (accessed on 12 August 2020).

9. Xiang, D.; Wang, X.; Jia, C.; Lee, T.; Guo, X. Molecular-Scale Electronics: From Concept to Function. Chem. Rev. 2016, 116, 4318-4440. [CrossRef] [PubMed]

10. Tao, N.J. Electron Transport in Molecular Junctions. Nat. Nanotechnol. 2006, 1, 173-181. [CrossRef] [PubMed]

11. McCreery, R.L.; Yan, H.; Bergren, A.J. A Critical Perspective on Molecular Electronic Junctions: There Is Plenty of Room in the Middle. Phys. Chem. Chem. Phys. 2013, 15, 1065-1081. [CrossRef]

12. Sun, L.; Diaz-Fernandez, Y.A.; Gschneidtner, T.A.; Westerlund, F.; Lara-Avila, S.; Moth-Poulsen, K. Single-Molecule Electronics: From Chemical Design to Functional Devices. Chem. Soc. Rev. 2014, 43, 7378-7411. [CrossRef]

13. Xin, N.; Guan, J.; Zhou, C.; Chen, X.; Gu, C.; Li, Y.; Ratner, M.A.; Nitzan, A.; Stoddart, J.F.; Guo, X. Concepts in the Design and Engineering of Single-Molecule Electronic Devices. Nat. Rev. Phys. 2019, 1, 211-230. [CrossRef]

14. Haiss, W.; Wang, C.; Grace, I.; Batsanov, A.S.; Schiffrin, D.J.; Higgins, S.J.; Bryce, M.R.; Lambert, C.J.; Nichols, R.J. Precision Control of Single-Molecule Electrical Junctions. Nat. Mater. 2006, 5, 995-1002. [CrossRef]

15. Aviram, A.; Ratner, M. Molecular Rectifiers. Chem. Phys. Lett. 1974, 29, 277-283. [CrossRef]

16. Richter, L.J.; Yang, C.S.-C.; Wilson, P.T.; Hacker, C.A.; van Zee, R.D.; Stapleton, J.J.; Allara, D.L.; Yao, Y.; Tour, J.M. Optical Characterization of Oligo(Phenylene-ethynylene) Self-Assembled Monolayers on Gold. J. Phys. Chem. B 2004, 108, 12547-12559. [CrossRef]

17. Akkerman, H.B.; de Boer, B. Electrical Conduction through Single Molecules and Self-Assembled Monolayers. J. Phys. Condens. Matter 2008, 20, 013001. [CrossRef]

18. Haiss, W.; Albrecht, T.; Van Zalinge, H.; Higgins, S.J.; Bethell, D.; Höbenreich, H.; Schiffrin, D.J.; Nichols, R.J.; Kuznetsov, A.M.; Zhang, J.; et al. Single-Molecule Conductance of Redox Molecules in Electrochemical Scanning Tunneling Microscopy. J. Phys. Chem. B 2007, 111, 6703-6712. [CrossRef] [PubMed]

19. He, J.; Sankey, O.; Lee, M.; Tao, N.; Li, X.; Lindsay, S. Measuring Single Molecule Conductance with Break Junctions. Faraday Discuss. 2006, 131, 145-154. [CrossRef] [PubMed]

20. Hines, T.; Díez-Perez, I.; Hihath, J.; Liu, H.; Wang, Z.S.; Zhao, J.; Zhou, G.; Müllen, K.; Tao, N. Transition from Tunneling to Hopping in Single Molecular Junctions by Measuring Length and Temperature Dependence. J. Am. Chem. Soc. 2010, 132, 11658-11664. [CrossRef] [PubMed]

21. Ballesteros, L.M.; Martín, S.; Marqués-González, S.; López, M.C.; Higgins, S.J.; Nichols, R.J.; Low, P.J.; Cea, P. Single Gold Atom Containing Oligo(Phenylene)Ethynylene: Assembly into LB Films and Electrical Characterization. J. Phys. Chem. C 2015, 119, 784-793. [CrossRef]

22. Vuillaume, D. Molecular Electronics: From Single-Molecule to Large-Area Devices. Chempluschem 2019, 84, 1215-1221. [CrossRef] [PubMed]

23. Wu, S.; González, M.T.; Huber, R.; Grunder, S.; Mayor, M.; Schönenberger, C.; Calame, M. Molecular Junctions Based on Aromatic Coupling. Nat. Nanotechnol. 2008, 3, 569-574. [CrossRef]

24. Chen, F.; Li, X.; Hihath, J.; Huang, Z.; Tao, N. Effect of Anchoring Groups on Single-Molecule Conductance: Comparative Study of Thiol-, Amine-, and Carboxylic-Acid-Terminated Molecules. J. Am. Chem. Soc. 2006, 128, 15874-15881. [CrossRef]

25. Kaliginedi, V.; Rudnev, A.V.; Moreno-García, P.; Baghernejad, M.; Huang, C.; Hong, W.; Wandlowski, T. Promising Anchoring Groups for Single-Molecule Conductance Measurements. Phys. Chem. Chem. Phys. 2014, 16, 23529-23539. [CrossRef]

26. Leary, E.; La Rosa, A.; Gonzalez, M.T.; Rubio-Bollinger, G.; Agrait, N.; Martin, N. Incorporating Single Molecules into Electrical Circuits. The Role of the Chemical Anchoring Group. Chem. Soc. Rev. 2015, 44, 920-942. [CrossRef]

27. Venkataraman, L.; Klare, J.E.; Nuckolls, C.; Hybertsen, M.S.; Steigerwald, M.L. Dependence of Single-Molecule Junction Conductance on Molecular Conformation. Nature 2006, 442, 904-907. [CrossRef] 
28. Bock, S.; Al-owaedi, O.A.; Eaves, S.G.; Milán, D.C.; Lemmer, M.; Skelton, B.W.; Osorio, H.M.; Higgins, S.J.; Cea, P.; Long, N.J.; et al. Single-Molecule Conductance Studies of Organometallic Complexes Bearing 3-Thienyl Contacting Groups. Chem. Eur. J. 2017, 23, 2133-2143. [CrossRef] [PubMed]

29. Haiss, W.; Van Zalinge, H.; Higgins, S.J.; Bethell, D.; Höbenreich, H.; Schiffrin, D.J.; Nichols, R.J. Redox State Dependence of Single Molecule Conductivity. J. Am. Chem. Soc. 2003, 125, 15294-15295. [CrossRef]

30. Janin, M.; Ghilane, J.; Lacroix, J.C. When Electron Transfer Meets Electron Transport in Redox-Active Molecular Nanojunctions. J. Am. Chem. Soc. 2013, 135, 2108-2111. [CrossRef] [PubMed]

31. Chen, C.P.; Luo, W.R.; Chen, C.N.; Wu, S.M.; Hsieh, S.; Chiang, C.M.; Dong, T.Y. Redox-Active $\pi$-Conjugated Organometallic Monolayers: Pronounced Coulomb Blockade Characteristic at Room Temperature. Langmuir 2013, 29, 3106-3115. [CrossRef]

32. Beebe, J.M.; Kim, B.S.; Frisbei, C.D.; Kushmerick, J.G. Measuring Relative Barrier Heights in Molecular Electronic Junctions with Transition Voltage Spectroscopy. ACS Nano 2008, 2, 827-832. [CrossRef]

33. Morteza Najarian, A.; Szeto, B.; Tefashe, U.M.; McCreery, R.L. Robust All-Carbon Molecular Junctions on Flexible or Semi-Transparent Substrates Using "Process-Friendly" Fabrication. ACS Nano 2016, 10, 8918-8928. [CrossRef]

34. Aragonès, A.C.; Darwish, N.; Ciampi, S.; Sanz, F.; Gooding, J.J.; Díez-Pérez, I. Single-Molecule Electrical Contacts on Silicon Electrodes under Ambient Conditions. Nat. Commun. 2017, 8, 15056. [CrossRef] [PubMed]

35. Jia, C.; Guo, X. Molecule-Electrode Interfaces in Molecular Electronic Devices. Chem. Soc. Rev. 2013, 42, 5642-5660. [CrossRef]

36. Brooke, R.J.; Bryce, M.R.; Cea, P.; Ferrer, J.; Higgins, S.J.; Lambert, C.J.; Low, P.J.; Manrique, D.Z.; Martin, S.; Nichols, R.J.; et al. Solvent Dependence of the Single Molecule Conductance of Oligoyne-Based Molecular Wires. J. Phys. Chem. C 2016, 120, 15666-15674.

37. Ballesteros, L.M.; Martín, S.; Cortés, J.; Marqués-González, S.; Higgins, S.J.; Nichols, R.J.; Low, P.J.; Cea, P. Controlling the Structural and Electrical Properties of Diacid Oligo (Phenyl Ene Ethynylene) Langmuir-Blodgett Films. Chem. Eur. J. 2013, 19, 5352-5363. [CrossRef]

38. Wang, W.; Lee, T.; Reed, M.A. Electron Tunnelling in Self-Assembled Monolayers. Rep. Prog. Phys. 2005, 68, 523-544. [CrossRef]

39. Luo, L.; Choi, S.H.; Frisbie, C.D. Probing Hopping Conduction in Conjugated Molecular Wires Connected to Metal Electrodes. Chem. Mater. 2011, 23, 631-645. [CrossRef]

40. Zhao, X.; Huang, C.; Gulcur, M.; Batsanov, A.S.; Baghernejad, M.; Hong, W.; Bryce, M.R.; Wandlowski, T. Oligo(Aryleneethynylene)s with Terminal Pyridyl Groups: Synthesis and Length Dependence of the Tunneling-to-Hopping Transition of Single-Molecule Conductances. Chem. Mater. 2013, 25, 4340-4347. [CrossRef]

41. Bumm, L.A.; Arnold, J.J.; Cygan, M.T.; Dunbar, T.D.; Burgin, T.P.; Jones, L.; Allara, D.L.; Tour, J.M.; Weiss, P.S. Are Single Molecular Wires Conducting? Science 1996, 271, 1705-1707. [CrossRef]

42. Jia, C.; Agostino, M.; Na, X.; Shaoyun, H.; Jinying, W.; Qi, Y.; Shuopei, W.; Hongliang, C.; Duoming, W.; Boyong, F; et al. Covalently Bonded Single-Molecule Junctions with Stable and Reversible Photoswitched Conductivity. Science 2016, 352, 1443-1446. [CrossRef] [PubMed]

43. Capozzi, B.; Xia, J.; Adak, O.; Dell, E.J.; Liu, Z.F.; Taylor, J.C.; Neaton, J.B.; Campos, L.M.; Venkataraman, L. Single-Molecule Diodes with High Rectification Ratios through Environmental Control. Nat. Nanotechnol. 2015, 10, 522-527. [CrossRef]

44. Guo, C.; Wang, K.; Zerah-Harush, E.; Hamill, J.; Wang, B.; Dubi, Y.; Xu, B. Molecular Rectifier Composed of DNA with High Rectification Ratio Enabled by Intercalation. Nat. Chem. 2016, 8, 484-490. [CrossRef]

45. Osorio, H.M.; Catarelli, S.; Cea, P.; Gluyas, J.B.G.; Hartl, F.; Higgins, S.J.; Leary, E.; Low, P.J.; Martín, S.; Nichols, R.J.; et al. Electrochemical Single-Molecule Transistors with Optimized Gate Coupling. J. Am. Chem. Soc. 2015, 137, 14319-14328. [CrossRef]

46. Reecht, G.; Scheurer, F.; Speisser, V.; Dappe, Y.J.; Mathevet, F.; Schull, G. Electroluminescence of a Polythiophene Molecular Wire Suspended between a Metallic Surface and the Tip of a Scanning Tunneling Microscope. Phys. Rev. Lett. 2014, 112, 047403. [CrossRef]

47. Does Molecular Electronics Compute? Nat. Nanotechnol. 2013, 8, 377-389. [CrossRef]

48. Grupe, C. Visions for a Molecular Future. Nat. Nanotechnol. 2013, 8, 385-389.

49. Xin, N.; Guo, X. Catalyst: The Renaissance of Molecular Electronics. Chem 2017, 3, 373-376. [CrossRef] 
50. Hsu, L.Y.; Jin, B.Y.; Chen, C.H.; Peng, S.M. Reaction: New Insights into Molecular Electronics. Chem 2017, 3 , 378-379. [CrossRef]

51. Halik, M.; Klauk, H.; Zschieschang, U.; Maisch, S.; Effenberger, F.; Dehm, C.; Schu, M.; Brunnbauer, M.; Stellacci, F. Low-Voltage Organic Transistors with an Amorphous Molecular Gate Dielectric Marcus. Nature 2004, 431, 963-966. [CrossRef]

52. Aragonès, A.C.; Haworth, N.L.; Darwish, N.; Ciampi, S.; Bloomfield, N.J.; Wallace, G.G.; Diez-Perez, I.; Coote, M.L. Electrostatic Catalysis of a Diels-Alder Reaction. Nature 2016, 531, 88-91. [CrossRef]

53. Ciampi, S.; Darwish, N.; Aitken, H.M.; Díez-Perez, I.; Coote, M.L. Harnessing Electrostatic Catalysis in Single Molecule, Electrochemical and Chemical Systems: A Rapidly Growing Experimental Tool Box. Chem. Soc. Rev. 2018, 47, 5146-5164. [CrossRef]

54. Metzger, R.M. Unimolecular Electronics. Chem. Rev. 2015, 115, 5056-5115. [CrossRef]

55. Pobelov, I.V.; Li, Z.; Wandlowski, T. Electrolyte Gating in Redox-Active Tunneling Junctions-An Electrochemical STM Approach. J. Am. Chem. Soc. 2008, 130, 16045-16054. [CrossRef]

56. Baghernejad, M.; Manrique, D.Z.; Li, C.; Pope, T.; Zhumaev, U.; Pobelov, I.; Kaliginedi, V.; Huang, C.; Hong, W.; Lambert, C.; et al. Highly-Effective Gating of Single-Molecule Junctions: An Electrochemical Approach. Chem. Commun. 2014, 50, 15975-15978. [CrossRef]

57. Darwish, N.; Díez-Pérez, I.; Guo, S.; Tao, N.; Gooding, J.J.; Paddon-Row, M.N. Single Molecular Switches: Electrochemical Gating of a Single Anthraquinone-Based Norbornylogous Bridge Molecule. J. Phys. Chem. C 2012, 116, 21093-21097. [CrossRef]

58. Haga, M.A.; Kobayashi, K.; Terada, K. Fabrication and Functions of Surface Nanomaterials Based on Multilayered or Nanoarrayed Assembly of Metal Complexes. Coord. Chem. Rev. 2007, 251, 2688-2701. [CrossRef]

59. Rocha, A.R.; García-Suárez, V.M.; Bailey, S.W.; Lambert, C.J.; Ferrer, J.; Sanvito, S. Towards Molecular Spintronics. Nat. Mater. 2005, 4, 335-339. [CrossRef] [PubMed]

60. Schmaus, S.; Bagrets, A.; Nahas, Y.; Yamada, T.K.; Bork, A.; Bowen, M.; Beaurepaire, E.; Evers, F.; Wulfhekel, W. Giant Magnetoresistance through a Single Molecule. Nat. Nanotechnol. 2011, 6, 185-189. [CrossRef] [PubMed]

61. Aradhya, S.V.; Venkataraman, L. Single-Molecule Junctions beyond Electronic Transport. Nat. Nanotechnol. 2013, 8, 399-410. [CrossRef]

62. Ormaza, M.; Abufager, P.; Verlhac, B.; Bachellier, N.; Bocquet, M.L.; Lorente, N.; Limot, L. Controlled Spin Switching in a Metallocene Molecular Junction. Nat. Commun. 2017, 8, 1974. [CrossRef]

63. Gehring, P.; Thijssen, J.M.; van der Zant, H.S.J. Single-Molecule Quantum-Transport Phenomena in Break Junctions. Nat. Rev. Phys. 2019, 1, 381-396. [CrossRef]

64. Park, S.; Kang, H.; Yoon, H.J. Structure-Thermopower Relationships in Molecular Thermoelectrics. J. Mater. Chem. A 2019, 7, 14419-14446. [CrossRef]

65. Perroni, C.A.; Ninno, D.; Cataudella, V. Thermoelectric Efficiency of Molecular Junctions. J. Phys. Condens. Matter 2016, 28, 373001. [CrossRef]

66. Harzheim, A. Thermoelectricity in Single-Molecule Devices. Mater. Sci. Technol. 2018, 34, 1275-1286. [CrossRef]

67. Cui, L.; Miao, R.; Jiang, C.; Meyhofer, E.; Reddy, P. Perspective: Thermal and Thermoelectric Transport in Molecular Junctions. J. Chem. Phys. 2017, 146, 092201. [CrossRef]

68. Cui, L.; Miao, R.; Wang, K.; Thompson, D.; Zotti, L.A.; Cuevas, J.C.; Meyhofer, E.; Reddy, P. Peltier Cooling in Molecular Junctions. Nat. Nanotechnol. 2018, 13, 122-127. [CrossRef]

69. Gao, W.; Ota, H.; Kiriya, D.; Takei, K.; Javey, A. Flexible Electronics toward Wearable Sensing. Acc. Chem. Res. 2019, 52, 523-533. [CrossRef] [PubMed]

70. Wang, S.; Oh, J.Y.; Xu, J.; Tran, H.; Bao, Z. Skin-Inspired Electronics: An Emerging Paradigm. Acc. Chem. Res. 2018, 51, 1033-1045. [CrossRef] [PubMed]

71. Gao, M.; Shih, C.; Chen, W. Advances and Challenges of Green Materials for Electronics and Energy Storage Applications: From Design to End-of-Life Recovery. J. Mater. Chem. A 2018, 6, 20546-20563. [CrossRef]

72. Bergren, A.J.; Zeer-Wanklyn, L.; Semple, M.; Pekas, N.; Szeto, B.; McCreery, R.L. Musical Molecules: The Molecular Junction as an Active Component in Audio Distortion Circuits. J. Phys. Condens. Matter 2016, 28, 094011. [CrossRef] [PubMed]

73. Lörtscher, E. Reaction: Technological Aspects of Molecular Electronics. Chem 2017, 3, 376-377. [CrossRef] 
74. Martín, S.; Haiss, W.; Higgins, S.; Cea, P.; López, M.C.; Nichols, R.J. A Comprehensive Study of the Single Molecule Conductance of $\alpha, \omega$-Dicarboxylic Acid-Terminated Alkanes. J. Phys. Chem. C 2008, 112, 3941-3948. [CrossRef]

75. Xing, Y.; Park, T.H.; Venkatramani, R.; Keinan, S.; Beratan, D.N.; Therien, M.J.; Borguet, E. Optimizing Single-Molecule Conductivity of Conjugated Organic Oligomers with Carbodithioate Linkers. J. Am. Chem. Soc. 2010, 132, 7946-7956. [CrossRef]

76. Cheng, Z.-L.; Skouta, R.; Vazquez, H.; Widawsky, J.R.; Schneebeli, S.; Chen, W.; Hybertsen, M.S.; Breslow, R.; Venkataraman, L. In Situ Formation of Highly Conducting Covalent Au-C Contacts for Single-Molecule Junctions. Nat. Nanotechnol. 2011, 6, 353-357. [CrossRef]

77. Weibel, N.; Błaszczyk, A.; von Hänisch, C.; Mayor, M.; Pobelov, I.; Wandlowski, T.; Chen, F.; Tao, N. Redox-Active Catechol-Functionalized Molecular Rods: Suitable Protection Groups and Single-Molecule Transport Investigations. Eur. J. Org. Chem. 2008, 2008, 136-149. [CrossRef]

78. Arroyo, C.R.; Leary, E.; Castellanos-Gómez, A.; Rubio-Bollinger, G.; González, M.T.; Agraït, N. Influence of Binding Groups on Molecular Junction Formation. J. Am. Chem. Soc. 2011, 133, 14313-14319. [CrossRef] [PubMed]

79. Pera, G.; Villares, A.; López, M.C.; Cea, P.; Lydon, D.P.; Low, P.J. Preparation and Characterization of Langmuir and Langmuir-Blodgett Films from a Nitrile-Terminated Tolan. Chem. Mater. 2007, 19, 857-864. [CrossRef]

80. Ferradás, R.R.; Marqués-González, S.; Osorio, H.M.; Ferrer, J.; Cea, P.; Milan, D.C.; Vezzoli, A.; Higgins, S.J.; Nichols, R.J.; Low, P.J.; et al. Low Variability of Single-Molecule Conductance Assisted by Bulky Metal-Molecule Contacts. RSC Adv. 2016, 6, 75111-75121. [CrossRef]

81. Herrer, I.L.; Ismael, A.K.; Milán, D.C.; Vezzoli, A.; Martín, S.; González-Orive, A.; Grace, I.; Lambert, C.; Serrano, J.L.; Nichols, R.J.; et al. Unconventional Single-Molecule Conductance Behavior for a New Heterocyclic Anchoring Group: Pyrazolyl. J. Phys. Chem. Lett. 2018, 9, 5364-5372. [CrossRef]

82. Valášek, M.; Lindner, M.; Mayor, M. Rigid Multipodal Platforms for Metal Surfaces. Beilstein J. Nanotechnol. 2016, 7, 374-405. [CrossRef]

83. Osorio, H.M.; Martín, S.; Milan, D.C.; González-Orive, A.; Gluyas, J.B.G.; Higgins, S.J.; Low, P.J.; Nichols, R.J.; Cea, P. Influence of Surface Coverage on the Formation of 4,4'-Bipyridinium (Viologen) Single Molecular Junctions. J. Mater. Chem. C 2017, 5, 11717-11723. [CrossRef]

84. Walker, A.V. Toward a New World of Molecular Devices: Making Metallic Contacts to Molecules. J. Vac. Sci. Technol. A 2013, 31, 050816. [CrossRef]

85. Haick, H.; Cahen, D. Making Contact: Connecting Molecules Electrically to the Macroscopic World. Prog. Surf. Sci. 2008, 83, 217-261. [CrossRef]

86. Song, F.; Wells, J.W.; Handrup, K.; Li, Z.S.; Bao, S.N.; Schulte, K.; Ahola-Tuomi, M.; Mayor, L.C.; Swarbrick, J.C.; Perkins, E.W.; et al. Direct Measurement of Electrical Conductance through a Self-Assembled Molecular Layer. Nat. Nanotechnol. 2009, 4, 373-376. [CrossRef]

87. Low, P.J. Twists and Turns: Studies of the Complexes and Properties of Bimetallic Complexes Featuring Phenylene Ethynylene and Related Bridging Ligands. Coord. Chem. Rev. 2013, 257, 1507-1532. [CrossRef]

88. Higgins, S.J.; Nichols, R.J.; Martin, S.; Cea, P.; Van Der Zant, H.S.J.; Richter, M.M.; Low, P.J. Looking Ahead: Challenges and Opportunities in Organometallic Chemistry. Organometallics 2011, 30, 7-12. [CrossRef]

89. Yao, H.; Cui, Y.; Yu, R.; Gao, B.; Zhang, H.; Hou, J. Design, Synthesis, and Photovoltaic Characterization of a Small Molecular Acceptor with an Ultra-Narrow Band Gap. Angew. Chem. Int. Ed. 2017, 56, 3045-3049. [CrossRef]

90. Vilan, A.; Aswal, D.; Cahen, D. Large-Area, Ensemble Molecular Electronics: Motivation and Challenges. Chem. Rev. 2017, 117, 4248-4286. [CrossRef]

91. Cea, P.; Ballesteros, L.M.; Martín, S. Nanofabrication Techniques of Highly Organized Monolayers Sandwiched between Two Electrodes for Molecular Electronics. Nanofabrication 2014, 1, 96-117. [CrossRef]

92. Ramachandran, G.K.; Hopson, T.J.; Rawlett, A.M.; Nagahara, L.A.; Primak, A.; Lindsay, S.M. A Bond-Fluctuation Mechanism for Stochastic Switching in Wired Molecules. Science 2003, 300, 1413-1416. [CrossRef]

93. Denayer, J.; Delhalle, J.; Mekhalif, Z. Comparative Study of Copper Surface Treatment with Self-Assembled Monolayers of Aliphatic Thiol, Dithiol and Dithiocarboxylic Acid. J. Electroanal. Chem. 2009, 637, 43-49. [CrossRef]

94. Adaligil, E.; Shon, Y.-S.; Slowinski, K. Effect of Headgroup on Electrical Conductivity of Self-Assembled Monolayers on Mercury: N-Alkanethiols versus n-Alkaneselenols. Langmuir 2010, 26, 1570-1573. [CrossRef] 
95. Beebe, J.M.; Engelkes, V.B.; Miller, L.L.; Frisbie, C.D. Contact Resistance in Metal-Molecule-Metal Junctions Based on Aliphatic SAMs: Effects of Surface Linker and Metal Work Function. J. Am. Chem. Soc. 2002, 124, 11268-11269. [CrossRef]

96. Tsunoi, A.; Lkhamsuren, G.; Angelo, E.; Mondarte, Q.; Asatyas, S.; Oguchi, M.; Noh, J.; Hayashi, T. Improvement of the Thermal Stability of Self-Assembled Monolayers of Isocyanide Derivatives on Gold. J. Phys. Chem. C 2019, 123, 13681-13686. [CrossRef]

97. Huo, L.; Du, P.; Zhou, H.; Zhang, K.; Liu, P. Fabrication and Tribological Properties of Self-Assembled Monolayer of n-Alkyltrimethoxysilane on Silicon: Effect of SAM Alkyl Chain Length. Appl. Surf. Sci. 2017, 396, 865-869. [CrossRef]

98. Wan, X.; Lieberman, I.; Asyuda, A.; Resch, S.; Seim, H.; Zharnikov, M. Thermal Stability of Phosphonic Acid Self-Assembled Monolayers on Alumina Substrates. J. Phys. Chem. C 2020, 124, 2531-2542. [CrossRef]

99. Adenier, A.; Chehimi, M.M.; Gallardo, I.; Pinson, J.; Vilà, N. Electrochemical Oxidation of Aliphatic Amines and Their Attachment to Carbon and Metal Surfaces. Langmuir 2004, 20, 8243-8253. [CrossRef] [PubMed]

100. Rittikulsittichai, S.; Park, C.S.; Jamison, A.C.; Rodriguez, D.; Zenasni, O.; Lee, T.R. Bidentate Aromatic Thiols on Gold: New Insight Regarding the Influence of Branching on the Structure, Packing, Wetting, and Stability of Self-Assembled Monolayers on Gold Surfaces. Langmuir 2017, 33, 4396-4406. [CrossRef]

101. Pathak, A.; Bora, A.; Liao, K.-C.; Schmolke, H.; Jung, A.; Klages, C.-P.; Schwartz, J.; Tornow, M. Disorder-Derived, Strong Tunneling Attenuation in Bis-Phosphonate Monolayers. J. Phys. Condens. Matter 2016, 28, 094008. [CrossRef] [PubMed]

102. Hopmann, E.; Elezzabi, A.Y. Electrochemical Stability Enhancement of Electrochromic Tungsten Oxide by Self-Assembly of a Phosphonate Protection Layer. ACS Appl. Mater. Interfaces 2020, 12, 1930-1936. [CrossRef] [PubMed]

103. Camacho-Alanis, F.; Wu, L.; Zangari, G.; Swami, N. Molecular Junctions of $\sim 1$ Nm Device Length on Self-Assembled Monolayer Modified n- vs. p-GaAs. J. Mater. Chem. 2008, 18, 5459-5467. [CrossRef]

104. Villares, A.; Pera, G.; Lydon, D.P.; López, M.C.; Low, P.J.; Cea, P. Mixing Behaviour of a Conjugated Molecular Wire Candidate and an Insulating Fatty Acid within Langmuir-Blodgett Films. Colloids Surf. A Physicochem. Eng. Asp. 2009, 346, 170-176. [CrossRef]

105. Bartl, J.D.; Gremmo, S.; Stutzmann, M.; Tornow, M.; Cattani-Scholz, A. Modification of Silicon Nitride with Oligo(Ethylene Glycol)-Terminated Organophosphonate Monolayers. Surf. Sci. 2020, 697, 121599. [CrossRef]

106. Qiu, X.; Ivasyshyn, V.; Qiu, L.; Enache, M.; Dong, J.; Rousseva, S.; Portale, G.; Stöhr, M.; Hummelen, J.C.; Chiechi, R.C. Thiol-Free Self-Assembled Oligoethylene Glycols Enable Robust Air-Stable Molecular Electronics. Nat. Mater. 2020, 19, 330-337. [CrossRef]

107. Moneo, A.; Gonzalez-Orive, A.; Bock, S.; Fenero, M.; Herrer, L.; Costa-Milan, D.; Lorenzoni, M.; Nichols, R.J.; Cea, P.; Perez-Murano, F.; et al. Towards Molecular Electronic Devices Based on "all-Carbon" Wires. Nanoscale 2018, 10, 14128-14138. [CrossRef] [PubMed]

108. Gulcur, M.; Moreno-garcía, P.; Zhao, X.; Baghernejad, M. The Synthesis of Functionalised Diaryltetraynes and Their Transport Properties in Single-Molecule Junctions. Chem. Eur. J. 2014, 20, 4653-4660. [CrossRef]

109. Donhauser, Z.J.; Mantooth, B.A.; Kelly, K.F.; Bumm, L.A.; Monnell, J.D.; Stapleton, J.J.; Price, D.W.; Rawlett, A.M.; Allara, D.L.; Tour, J.M.; et al. Conductance Switching in Single Molecules Through Conformational Changes. Science 2001, 292, 2303-2307. [CrossRef] [PubMed]

110. Lu, Q.; Liu, K.; Zhang, H.; Du, Z.; Wang, X.; Wang, F. From Tunneling to Hopping: A Comprehensive Investigation of Charge. ACS Nano 2009, 3, 3861-3868. [CrossRef] [PubMed]

111. Herrer, L.; Sebastian, V.; Martín, S.; González-orive, A.; Pérez-Murano, F.; Low, P.J.; Serrano, J.L.; Santamaría, J.; Cea, P. High Surface Coverage of a Self-Assembled Monolayer by in Situ Synthesis of Palladium Nanodeposits. Nanoscale 2017, 9, 13281-13291. [CrossRef]

112. Herrer, L.; González-Orive, A.; Marqués-González, S.; Martín, S.; Nichols, R.J.; Serrano, J.L.; Low, P.J.; Cea, P. Electrically Transmissive Alkyne-Anchored Monolayers on Gold. Nanoscale 2019, 11, 7976-7985. [CrossRef]

113. Pera, G.; Martín, S.; Ballesteros, L.M.; Hope, A.J.; Low, P.J.; Nichols, R.J.; Cea, P. Metal-Molecule-Metal Junctions in Langmuir-Blodgett Films Using a New Linker: Trimethylsilane. Chem. Eur. J. 2010, 16, 13398-13405. [CrossRef]

114. Ballesteros, L.M.; Martín, S.; Pera, G.; Schauer, P.A.; Kay, N.J.; López, M.C.; Low, P.J.; Nichols, R.J.; Cea, P. Directionally Oriented LB Films of an OPE Derivative: Assembly, Characterization, and Electrical Properties. Langmuir 2011, 27, 3600-3610. [CrossRef] 
115. Martín, S.; Ballesteros, L.M.; González-Orive, A.; Oliva, H.; Marqués-González, S.; Lorenzoni, M.; Nichols, R.J.; Pérez-Murano, F.; Low, P.J.; Cea, P. Towards a Metallic Top Contact Electrode in Molecular Electronic Devices Exhibiting a Large Surface Coverage by Photoreduction of Silver Cations. J. Mater. Chem. C 2016, 4, 9036-9043. [CrossRef]

116. Villares, A.; Lydon, D.P.; Porrés, L.; Beeby, A.; Low, P.J.; Cea, P.; Royo, F.M. Preparation of Ordered Films Containing a Phenylene Ethynylene Oligomer by the Langmuir-Blodgett Technique. J. Phys. Chem. B 2007, 111, 7201-7209. [CrossRef]

117. Sangiao, S.; Martín, S.; González-Orive, A.; Magén, C.; Low, P.J.; De Teresa, J.M.; Cea, P. All-Carbon Electrode Molecular Electronic Devices Based on Langmuir-Blodgett Monolayers. Small 2017, 13, 1603207. [CrossRef] [PubMed]

118. Villares, A.; Pera, G.; Martin, S.; Nichols, R.J.; Lydon, D.P.; Applegarth, L.; Beeby, A.; Low, P.J.; Cea, P. Fabrication, Characterization, and Electrical Properties of Langmuir-Blodgett Films of an Acid Terminated Phenylene-Ethynylene Oligomer. Chem. Mater. 2010, 22, 2041-2049. [CrossRef]

119. Osorio, H.M.; Cea, P.; Ballesteros, L.M.; Gascón, I.; Marqués-González, S.; Nichols, R.J.; Pérez-Murano, F.; Low, P.J.; Martín, S. Preparation of Nascent Molecular Electronic Devices from Gold Nanoparticles and Terminal Alkyne Functionalised Monolayer Films. J. Mater. Chem. C 2014, 2, 7348-7355. [CrossRef]

120. Ballesteros, L.M.; Martín, S.; Momblona, C.; Marqués-González, S.; López, M.C.; Nichols, R.J.; Low, P.J.; Cea, P. Acetylene Used as a New Linker for Molecular Junctions in Phenylene-Ethynylene Oligomer Langmuir-Blodgett Films. J. Phys. Chem. C 2012, 116, 9142-9150. [CrossRef]

121. Villares, A.; Lydon, D.P.; Robinson, B.J.; Ashwell, G.J.; Royo, F.M.; Low, P.J.; Cea, P. Langmuir-Blodgett Films Incorporating Molecular Wire Candidates of Ester-Substituted Oligo(Phenylene-Ethynylene) Derivatives. Surf. Sci. 2008, 602, 3683-3687. [CrossRef]

122. Casalini, S.; Berto, M.; Leonardi, F.; Operamolla, A.; Bortolotti, C.A.; Borsari, M.; Sun, W.; Di Felice, R.; Corni, S.; Albonetti, C.; et al. Self-Assembly of Mono- and Bidentate Oligoarylene Thiols onto Polycrystalline Au. Langmuir 2013, 29, 13198-13208. [CrossRef]

123. Von Wrochem, F.; Gao, D.; Scholz, F.; Nothofer, H.-G.; Nelles, G.; Wessels, J.M. Efficient Electronic Coupling and Improved Stability with Dithiocarbamate-Based Molecular Junctions. Nat. Nanotechnol. 2010, 5, 618-624. [CrossRef]

124. Pla-Vilanova, P.; Aragonès, A.C.; Ciampi, S.; Sanz, F.; Darwish, N.; Díez-Pérez, I. The Spontaneous Formation of Single-Molecule Junctions via Terminal Alkynes. Nanotechnology 2015, 26, 381001. [CrossRef]

125. Osorio, H.M.; Martín, S.; López, M.C.; Marqués-González, S.; Higgins, S.J.; Nichols, R.J.; Low, P.J.; Cea, P. Electrical Characterization of Single Molecule and Langmuir-Blodgett Monomolecular Films of a Pyridine Terminated Oligo(Phenylene-Ethynylene) Derivative. Beilstein J. Nanotechnol. 2015, 6, 1145-1157. [CrossRef]

126. Escorihuela, E.; Cea, P.; Naghibi, S.; Osorio, H.M.; Martin, S.; Milan, D.C.; Nichols, R.J.; Low, P.J. Towards the Design of Effective Multipodal Contacts for Use in the Construction of Langmuir-Blodgett Films and Molecular Junctions. J. Mater. Chem. A 2020, 8, 672-682. [CrossRef]

127. Herrer, L.; Ismael, A.; Martín, S.; Milan, D.C.C.; Serrano, J.L.L.; Nichols, R.J.J.; Lambert, C.; Cea, P. Single Molecule vs. Large Area Design of Molecular Electronic Devices Incorporating an Efficient 2-Aminepyridine Double Anchoring Group. Nanoscale 2019, 11, 15871-15880. [CrossRef] [PubMed]

128. Baranton, S.; Bélanger, D. In Situ Generation of Diazonium Cations in Organic Electrolyte for Electrochemical Modification of Electrode Surface. Electrochim. Acta 2008, 53, 6961-6967. [CrossRef]

129. Liu, W.; Tilley, T.D. Sterically Controlled Functionalization of Carbon Surfaces With- $\mathrm{C}_{6} \mathrm{H}_{4} \mathrm{CH}_{2} \mathrm{X}$ $\left(\mathrm{X}=\mathrm{OSO}_{2} \mathrm{Me}\right.$ or $\mathrm{N}_{3}$ ) Groups for Surface Attachment of Redox-Active Molecules. Langmuir 2015, 31, 1189-1195. [CrossRef] [PubMed]

130. Combellas, C.; Kanoufi, F.; Pinson, J.; Podvorica, F.I. Indirect Electrografting of Aryl Iodides. Electrochem. Commun. 2019, 98, 119-123. [CrossRef]

131. Ditzler, L.R.; Karunatilaka, C.; Donuru, V.R.; Liu, H.Y.; Tivanski, A.V. Electromechanical Properties of Self-Assembled Monolayers of Tetrathiafulvalene Derivatives Studied by Conducting Probe Atomic Force Microscopy. J. Phys. Chem. C 2010, 114, 4429-4435. [CrossRef]

132. Yokoyama, T.; Kawasaki, M.; Asari, T.; Ohno, S.; Tanaka, M.; Yoshimoto, Y. Adsorption and Self-Assembled Structures of Sexithiophene on the Si(111)- 3×3 -Ag Surface. J. Chem. Phys. 2015, 142, 204701. [CrossRef] 
133. Parry, A.V.S.; Lu, K.; Tate, D.J.; Urasinska-Wojcik, B.; Caras-Quintero, D.; Majewski, L.A.; Turner, M.L. Trichlorosilanes as Anchoring Groups for Phenylene-Thiophene Molecular Monolayer Field Effect Transistors. Adv. Funct. Mater. 2014, 24, 6677-6683. [CrossRef]

134. Sebechlebska, T.; Sebera, J.; Kolivoska, V.; Lindner, M.; Gasior, J.; Mészáros, G.; Valásek, M.; Mayor, M.; Hromadová, M. Investigation of the Geometrical Arrangement and Single Molecule Charge Transport in Self-Assembled Monolayers of Molecular Towers Based on Tetraphenylmethane Tripod. Electrochim. Acta 2017, 258, 1191-1200. [CrossRef]

135. Valášek, M.; Mayor, M.; Valáseck, M.; Mayor, M. Spatial and Lateral Control of Functionality by Rigid Molecular Platforms. Chem. Eur. J. 2017, 23, 13538-13548. [CrossRef]

136. Ye, Q.; Wang, H.; Yu, B.; Zhou, F. Self-Assembly of Catecholic Ferrocene and Electrochemical Behavior of Its Monolayer. RSC Adv. 2015, 5, 60090-60095. [CrossRef]

137. Ballesteros, L.M.; Martín, S.; Cortés, J.; Marqués-González, S.; Pérez-Murano, F.; Nichols, R.J.; Low, P.J.; Cea, P. From an Organometallic Monolayer to an Organic Monolayer Covered by Metal Nanoislands: A Simple Thermal Protocol for the Fabrication of the Top Contact Electrode in Molecular Electronic Devices. Adv. Mater. Interfaces 2014, 1, 1400128. [CrossRef]

138. Ezquerra, R.; Eaves, S.G.; Bock, S.; Skelton, B.W.; Pérez-Murano, F.; Cea, P.; Martín, S.; Low, P.J. New Routes to Organometallic Molecular Junctions: Via a Simple Thermal Processing Protocol. J. Mater. Chem. C 2019, 7, 6630-6640. [CrossRef]

139. Tefashe, U.M.; Van Nguyen, Q.; Lafolet, F.; Lacroix, J.C.; McCreery, R.L. Robust Bipolar Light Emission and Charge Transport in Symmetric Molecular Junctions. J. Am. Chem. Soc. 2017, 139, 7436-7439. [CrossRef] [PubMed]

140. Yasseri, A.A.; Syomin, D.; Malinovskii, V.L.; Loewe, R.S.; Lindsey, J.S.; Zaera, F.; Bocian, D.F. Characterization of Self-Assembled Monolayers of Porphyrins Bearing Multiple Thiol-Derivatized Rigid-Rod Tethers. J. Am. Chem. Soc. 2004, 126, 11944-11953. [CrossRef]

141. Otte, F.L.; Lemke, S.; Schütt, C.; Krekiehn, N.R.; Jung, U.; Magnussen, O.M.; Herges, R. Ordered Monolayers of Free-Standing Porphyrins on Gold. J. Am. Chem. Soc. 2014, 136, 11248-11251. [CrossRef]

142. He, W.-L.; Fang, F.; Ma, D.-M.; Chen, M.; Qian, D.-J.; Liu, M. Palladium-Directed Self-Assembly of Multi-Titanium(IV)-Porphyrin Arrays on the Substrate Surface as Sensitive Ultrathin Films for Hydrogen Peroxide Sensing, Photocurrent Generation, and Photochromism of Viologen. Appl. Surf. Sci. 2018, 427, 1003-1010. [CrossRef]

143. Kim, Y.-S.; Fournier, S.; Lau-Truong, S.; Decorse, P.; Devillers, C.H.; Lucas, D.; Harris, K.D.; Limoges, B.; Balland, V. Introducing Molecular Functionalities within High Surface Area Nanostructured ITO Electrodes through Diazonium Electrografting. ChemElectroChem 2018, 5, 1625-1630. [CrossRef]

144. Zhang, Z.; Yoshida, N.; Imae, T.; Xue, Q.; Bai, M.; Jiang, J.; Liu, Z. A Self-Assembled Monolayer of an Alkanoic Acid-Derivatized Porphyrin on Gold Surface: A Structural Investigation by Surface Plasmon Resonance, Ultraviolet-Visible, and Infrared Spectroscopies. J. Colloid Interface Sci. 2001, 243, 382-387. [CrossRef]

145. Bodik, M.; Maxian, O.; Hagara, J.; Nadazdy, P.; Jergel, M.; Majkova, E.; Siffalovic, P. Langmuir-Scheaffer Technique as a Method for Controlled Alignment of 1D Materials. Langmuir 2020, 36, 4540-4547. [CrossRef]

146. Kh Dzhanabekova, R.; Seliverstova, E.V.; Zh Zhumabekov, A.; Kh Ibrayev, N. Fabricating and Examining of Langmuir Films of Reduced Graphene Oxide. Russ. J. Phys. Chem. A 2019, 93, 284-289. [CrossRef]

147. Daraghma, S.M.A.; Talebi, S.; Zhijian, C.; Periasamy, V. Method of Assembling Pure Langmuir-Blodgett DNA Films Using TBE Buffer as the Subphase. Appl. Phys. A Mater. Sci. Process. 2019, 125, 593. [CrossRef]

148. Fereiro, J.A.; Yu, X.; Pecht, I.; Sheves, M.; Cuevas, J.C.; Cahen, D. Tunneling Explains Efficient Electron Transport via Protein Junctions. Proc. Natl. Acad. Sci. USA 2018, 115, E4577-E4583. [CrossRef] [PubMed]

149. Fereiro, J.A.; Kayser, B.; Romero-Muñiz, C.; Vilan, A.; Dolgikh, D.A.; Chertkova, R.V.; Cuevas, J.C.; Zotti, L.A.; Pecht, I.; Sheves, M.; et al. A Solid-State Protein Junction Serves as a Bias-Induced Current Switch. Angew. Chem. Int. Ed. 2019, 58, 11852-11859. [CrossRef] [PubMed]

150. Whitesides, G.; Grzybowski, B. Self-Assembly at All Scales. Science 2002, 295, 2418-2421. [CrossRef]

151. Casalini, S.; Bortolotti, C.A.; Leonardi, F.; Biscarini, F. Self-Assembled Monolayers in Organic Electronics. Chem. Soc. Rev. 2017, 46, 40-71. [CrossRef]

152. Desbief, S.; Patrone, L.; Goguenheim, D.; Guérin, D.; Vuillaume, D. Impact of Chain Length, Temperature, and Humidity on the Growth of Long Alkyltrichlorosilane Self-Assembled Monolayers. Phys. Chem. Chem. Phys. 2011, 13, 2870-2879. [CrossRef] 
153. Akkerman, H.B.; Kronemeijer, A.J.; Van Hal, P.A.; De Leeuw, D.M.; Blom, P.W.M.; De Boer, B. Self-Assembled-Monolayer Formation of Long Alkanedithiols in Molecular Junctions. Small 2008, 4, 100-104. [CrossRef]

154. Bigelow, W.C.; Pickett, D.L.; Zisman, W.A. Oleophobic Monolayers: I. Films Adsorbed from Solution in Non-Polar Liquids. J. Colloid Sci. 1946, 1, 513-538. [CrossRef]

155. Sagiv, J. Organized Monolayers by Adsorption. 1. Formation and Structure of Oleophobic Mixed Monolayers on Solid Surfaces. J. Am. Chem. Soc. 1980, 102, 92-98. [CrossRef]

156. Nuzzo, R.G.; Allara, D.L. Adsorption of Bifunctional Organic Disulfides on Gold Surfaces. J. Am. Chem. Soc. 1983, 105, 4481-4483. [CrossRef]

157. Ashwell, G.J.; Williams, A.T.; Barnes, S.A.; Chappell, S.L.; Phillips, L.J.; Robinson, B.J.; Urasinska-Wojcik, B.; Wierzchowiec, P.; Gentle, I.R.; Wood, B.J. Self-Assembly of Amino-Thiols via Gold-Nitrogen Links and Consequence for in Situ Elongation of Molecular Wires on Surface-Modified Electrodes. J. Phys. Chem. C 2011, 115, 4200-4208. [CrossRef]

158. Sims, R.A.; Harmer, S.L.; Quinton, J.S. The Role of Physisorption and Chemisorption in the Oscillatory Adsorption of Organosilanes on Aluminium Oxide. Polymers 2019, 11, 410. [CrossRef] [PubMed]

159. Salvarezza, R.C.; Carro, P. The Electrochemical Stability of Thiols on Gold Surfaces. J. Electroanal. Chem. 2018, 819, 234-239. [CrossRef]

160. Xie, Z.; Bâldea, I.; Frisbie, C.D. Determination of Energy-Level Alignment in Molecular Tunnel Junctions by Transport and Spectroscopy: Self-Consistency for the Case of Oligophenylene Thiols and Dithiols on Ag, Au, and Pt Electrodes. J. Am. Chem. Soc. 2019, 141, 3670-3681. [CrossRef] [PubMed]

161. Vericat, C.; Vela, M.E.; Benitez, G.; Carro, P.; Salvarezza, R.C. Self-Assembled Monolayers of Thiols and Dithiols on Gold: New Challenges for a Well-Known System. Chem. Soc. Rev. 2010, 39, 1805-1834. [CrossRef] [PubMed]

162. Muglali, M.I.; Erbe, A.; Chen, Y.; Barth, C.; Koelsch, P.; Rohwerder, M. Modulation of Electrochemical Hydrogen Evolution Rate by Araliphatic Thiol Monolayers on Gold. Electrochim. Acta 2013, 90, 17-26. [CrossRef]

163. Love, J.C.; Estroff, L.A.; Kriebel, J.K.; Nuzzo, R.G.; Whitesides, G.M. Self-Assembled Monolayers of Thiolates on Metals as a Form of Nanotechnology. Chem. Rev. 2005, 105, 1103-1169. [CrossRef]

164. Wang, Y.; Chi, Q.; Hush, N.S.; Reimers, J.R.; Zhang, J.; Ulstrup, J. Scanning Tunneling Microscopic Observation of Adatom-Mediated Motifs on Gold- Thiol Self-Assembled Monolayers at High Coverage. J. Phys. Chem. C 2009, 113, 19601-19608. [CrossRef]

165. Kim, C.M.; Bechhoefer, J. Conductive Probe AFM Study of Pt-Thiol and Au-Thiol Contacts in Metal-Molecule-Metal Systems. J. Chem. Phys. 2013, 138, 014707. [CrossRef]

166. Casalini, S.; Leonardi, F.; Bortolotti, C.A.; Operamolla, A.; Omar, O.H.; Paltrinieri, L.; Albonetti, C.; Farinola, G.M.; Biscarini, F. Mono/Bidentate Thiol Oligoarylene-Based Self-Assembled Monolayers (SAMs) for Interface Engineering. J. Mater. Chem. 2012, 22, 12155-12163. [CrossRef]

167. Gronbeck, H.; Curioni, A.; Andreoni, W. Thiols and Disulfides on the Au (111) Surface: The Headgroup Gold Interaction. J. Am. Chem. Soc. 2000, 122, 3839-3842. [CrossRef]

168. Bürgi, T. Properties of the Gold-Sulphur Interface: From Self-Assembled Monolayers to Clusters. Nanoscale 2015, 7, 15553-15567. [CrossRef] [PubMed]

169. Zhang, Y.; Qiu, X.; Gordiichuk, P.; Soni, S.; Krijger, T.L.; Herrmann, A.; Chiechi, R.C. Mechanically and Electrically Robust Self-Assembled Monolayers for Large-Area Tunneling Junctions. J. Phys. Chem. C 2017, 121, 14920-14928. [CrossRef] [PubMed]

170. Lindner, M.; Valášek, M.; Homberg, J.; Edelmann, K.; Gerhard, L.; Wulfhekel, W.; Fuhr, O.; Wächter, T.; Zharnikov, M.; Kolivoška, V.; et al. Importance of the Anchor Group Position (Para versus Meta) in Tetraphenylmethane Tripods: Synthesis and Self-Assembly Features. Chem. Eur. J. 2016, 22, 13218-13235. [CrossRef] [PubMed]

171. Carro, P.; Torrelles, X.; Salvarezza, R.C. A Novel Model for the $(\sqrt{ } 3 \times \sqrt{ } 3) R 30^{\circ}$ Alkanethiolate-Au(111) Phase Based on Alkanethiolate-Au Adatom Complexes. Phys. Chem. Chem. Phys. 2014, 16, 19017-19023. [CrossRef]

172. Xue, Y.; Li, X.; Li, H.; Zhang, W. Quantifying Thiol-Gold Interactions towards the Efficient Strength Control. Nat. Commun. 2014, 5, 4348. [CrossRef]

173. Miller, C.; Cuendet, P.; Graetzel, M. Adsorbed $\omega$-Hydroxy Thiol Monolayers on Gold Electrodes: Evidence for Electron Tunneling to Redox Species in Solution. J. Phys. Chem. 1991, 95, 877-886. [CrossRef] 
174. Porter, M.D.; Bright, T.B.; Allara, D.L.; Chidsey, C.E. Spontaneously Organized Molecular Assemblies. 4. Structural Characterization of n-Alkyl Thiol Monolayers on Gold by Optical Ellipsometry, Infrared Spectroscopy, and Electrochemistry. J. Am. Chem. Soc. 1987, 109, 3559-3568. [CrossRef]

175. Felgenhauer, T.; Rong, H.; Buck, M. Electrochemical and Exchange Studies of Self-Assembled Monolayers of Biphenyl Based Thiols on Gold. J. Electroanal. Chem. 2003, 551, 309-319. [CrossRef]

176. Reed, M.A.; Zhou, C.; Muller, C.J.; Burgin, T.P.; Tour, J.M. Conductance of a Molecular Junction. Science 1997, 278, 252-254. [CrossRef]

177. Dorogi, M.; Gomez, J.; Osifchin, R.; Andres, R.P.; Reifenberger, R. Room-Temperature Coulomb Blockade from a Self-Assembled Molecular Nanostructure. Phys. Rev. B 1995, 52, 9071-9077. [CrossRef] [PubMed]

178. Gittins, D.I.; Bethell, D.; Schiffrin, D.J.; Nichols, R.J. A Nanometre-Scale Electronic Switch Consisting of a Metal Cluster and Redox-Addressable Groups. Nature 2000, 408, 67-69. [CrossRef] [PubMed]

179. Cui, X.D.; Primak, A.; Zarate, X.; Tomfohr, J.; Sankey, O.F.; Moore, A.L.; Moore, T.A.; Gust, D.; Harris, G.; Lindsay, S.M. Reproducible Measurement of Single-Molecule Conductivity. Science 2001, 294, 571-574. [CrossRef] [PubMed]

180. Stapleton, J.J.; Harder, P.; Daniel, T.A.; Reinard, M.D.; Yao, Y.; Price, D.W.; Tour, J.M.; Allara, D.L. Self-Assembled Oligo(Phenylene-Ethynylene) Molecular Electronic Switch Monolayers on Gold: Structures and Chemical Stability. Langmuir 2003, 19, 8245-8255. [CrossRef]

181. Inkpen, M.S.; Liu, Z.; Li, H.; Campos, L.M.; Neaton, J.B.; Venkataraman, L. Non-Chemisorbed Gold-Sulfur Binding Prevails in Self-Assembled Monolayers. Nat. Chem. 2019, 11, 351-358. [CrossRef]

182. Kang, H.; Noh, J.; Ganbold, E.O.; Uuriintuya, D.; Gong, M.S.; Oh, J.J.; Joo, S.W. Adsorption Changes of Cyclohexyl Isothiocyanate on Gold Surfaces. J. Colloid Interface Sci. 2009, 336, 648-653. [CrossRef]

183. Katsonis, N.; Marchenko, A.; Taillemite, S.; Fichou, D.; Chouraqui, G.; Aubert, C.; Malacria, M. A Molecular Approach to Self-Assembly of Trimethylsilylacetylene Derivatives on Gold. Chem. Eur. J. 2003, 9, 2574-2581. [CrossRef]

184. Katsonis, N.; Marchenko, A.; Fichou, D.; Barrett, N. Investigation on the Nature of the Chemical Link between Acetylenic Organosilane Self-Assembled Monolayers and Au (111) by Means of Synchrotron Radiation Photoelectron Spectroscopy and Scanning Tunneling Microscopy. Surf. Sci. 2008, 602, 9-16. [CrossRef]

185. Bejarano, F.; Olavarria-Contreras, I.J.; Droghetti, A.; Rungger, I.; Rudnev, A.; Gutiérrez, D.; Mas-Torrent, M.; Veciana, J.; van der Zant, H.S.J.; Rovira, C.; et al. Robust Organic Radical Molecular Junctions Using Acetylene Terminated Groups for C-Au Bond Formation. J. Am. Chem. Soc. 2018, 140, 1691-1696. [CrossRef]

186. Eder, K.; Felfer, P.J.; Gault, B.; Ceguerra, A.V.; La Fontaine, A.; Masters, A.F.; Maschmeyer, T.; Cairney, J.M. A New Approach to Understand the Adsorption of Thiophene on Different Surfaces: An Atom Probe Investigation of Self-Assembled Monolayers. Langmuir 2017, 33, 9573-9581. [CrossRef]

187. Gu, C.; Zhang, J.L.; Sun, S.; Lian, X.; Ma, Z.; Mao, H.; Guo, L.; Wang, Y.; Chen, W. Molecular-Scale Investigation of the Thermal and Chemical Stability of Monolayer PTCDA on $\mathrm{Cu}(111)$ and $\mathrm{Cu}(110)$. ACS Appl. Mater. Interfaces 2020, 12, 22327-22334. [CrossRef] [PubMed]

188. Martin, C.A.; Ding, D.; Sørensen, J.K.; Bjørnholm, T.; van Ruitenbeek, J.M.; van der Zant, H.S.J. Fullerene-Based Anchoring Groups for Molecular Electronics. J. Am. Chem. Soc. 2008, 130, 13198-13199. [CrossRef] [PubMed]

189. Del Carmen Gimenez-Lopez, M.; Räisänen, M.T.; Chamberlain, T.W.; Weber, U.; Lebedeva, M.; Rance, G.A.; Andrew, G.; Briggs, D.; Pettifor, D.; Burlakov, V.; et al. Functionalized Fullerenes in Self-Assembled Monolayers. Langmuir 2011, 27, 10977-10985. [CrossRef] [PubMed]

190. Chinwangso, P.; Jamison, A.C.; Lee, T.R. Multidentate Adsorbates for Self-Assembled Monolayer Films. Acc. Chem. Res. 2011, 44, 511-519. [CrossRef] [PubMed]

191. Gao, D.; Scholz, F.; Nothofer, H.-G.; Ford, W.E.; Scherf, U.; Wessels, J.M.; Yasuda, A.; von Wrochem, F. Fabrication of Asymmetric Molecular Junctions by the Oriented Assembly of Dithiocarbamate Rectifiers. J. Am. Chem. Soc. 2011, 133, 5921-5930. [CrossRef]

192. Terada, K.I.; Nakamura, H.; Kanaizuka, K.; Haga, M.A.; Asai, Y.; Ishida, T. Long-Range Electron Transport of Ruthenium-Centered Multilayer Films via a Stepping-Stone Mechanism. ACS Nano 2012, 6, 1988-1999. [CrossRef]

193. Weidner, T.; Ballav, N.; Siemeling, U.; Troegel, D.; Walter, T.; Tacke, R.; Castner, D.G.; Zharnikov, M. Tripodal Binding Units for Self-Assembled Monolayers on Gold: A Comparison of Thiol and Thioether Headgroups. J. Phys. Chem. C 2009, 113, 19609-19617. [CrossRef] 
194. O’Driscoll, L.J.; Wang, X.; Jay, M.; Batsanov, A.S.; Sadeghi, H.; Lambert, C.J.; Robinson, B.J.; Bryce, M.R. Carbazole-Based Tetrapodal Anchor Groups for Gold Surfaces: Synthesis and Conductance Properties. Angew. Chem. Int. Ed. 2020, 59, 882-889. [CrossRef]

195. Darwish, N.; Aragonès, A.C.; Darwish, T.; Ciampi, S.; Díez-Pérez, I. Multi-Responsive Photo- and Chemo-Electrical Single-Molecule Switches. Nano Lett. 2014, 14, 7064-7070. [CrossRef]

196. Ie, Y.; Tanaka, K.; Tashiro, A.; Lee, S.K.; Testai, H.R.; Yamada, R.; Tada, H.; Aso, Y. Thiophene-Based Tripodal Anchor Units for Hole Transport in Single-Molecule Junctions with Gold Electrodes. J. Phys. Chem. Lett. 2015, 6, 3754-3759. [CrossRef]

197. Ie, Y.; Hirose, T.; Nakamura, H.; Kiguchi, M.; Takagi, N.; Kawai, M.; Aso, Y. Nature of Electron Transport by Pyridine-Based Tripodal Anchors: Potential for Robust and Conductive Single-Molecule Junctions with Gold Electrodes. J. Am. Chem. Soc. 2011, 133, 3014-3022. [CrossRef] [PubMed]

198. Gerhard, L.; Edelmann, K.; Homberg, J.; Valášek, M.; Bahoosh, S.G.; Lukas, M.; Pauly, F.; Mayor, M.; Wulfhekel, W. An Electrically Actuated Molecular Toggle Switch. Nat. Commun. 2017, 8, 14672. [CrossRef] [PubMed]

199. Kong, G.D.; Byeon, S.E.; Park, S.; Song, H.; Kim, S.Y.; Yoon, H.J. Mixed Molecular Electronics: Tunneling Behaviors and Applications of Mixed Self-Assembled Monolayers. Adv. Electron. Mater. 2020, 6, 1901157. [CrossRef]

200. Saegusa, T.; Sakai, H.; Nagashima, H.; Kobori, Y.; Tkachenko, N.V.; Hasobe, T. Controlled Orientations of Neighboring Tetracene Units by Mixed Self-Assembled Monolayers on Gold Nanoclusters for High-Yield and Long-Lived Triplet Excited States through Singlet Fission. J. Am. Chem. Soc. 2019, 141, 14720-14727. [CrossRef] [PubMed]

201. Huang, X.; Li, T. Recent Progress in the Development of Molecular-Scale Electronics Based on Photoswitchable Molecules. J. Mater. Chem. C 2020, 8, 821-848. [CrossRef]

202. Rohwerder, M.; de Weldige, K.; Stratmann, M. Potential Dependence of the Kinetics of Thiol Self-Organization on $\mathrm{Au}(111)$. J. Solid State Electrochem. 1998, 2, 88-93. [CrossRef]

203. Pillai, R.G.; Braun, M.D.; Freund, M.S. Electrochemically Assisted Self-Assembly of Alkylthiosulfates and Alkanethiols on Gold: The Role of Gold Oxide Formation and Corrosion. Langmuir 2010, 26, 269-276. [CrossRef]

204. Sahli, R.; Fave, C.; Raouafi, N.; Boujlel, K.; Schöllhorn, B.; Limoges, B. Switching On/Off the Chemisorption of Thioctic-Based Self-Assembled Monolayers on Gold by Applying a Moderate Cathodic/Anodic Potential. Langmuir 2013, 29, 5360-5368. [CrossRef]

205. Metoki, N.; Liu, L.; Beilis, E.; Eliaz, N.; Mandler, D. Preparation and Characterization of Alkylphosphonic Acid Self-Assembled Monolayers on Titanium Alloy by Chemisorption and Electrochemical Deposition. Langmuir 2014, 30, 6791-6799. [CrossRef]

206. Fioravanti, G.; Lugli, F.; Gentili, D.; Mucciante, V.; Leonardi, F.; Pasquali, L.; Liscio, A.; Murgia, M.; Zerbetto, F.; Cavallini, M. Electrochemical Fabrication of Surface Chemical Gradients in Thiol Self-Assembled Monolayers with Tailored Work-Functions. Langmuir 2014, 30, 11591-11598. [CrossRef]

207. Kwok, S.C.T.; Ciucci, F.; Yuen, M.M.F. Chemisorption Threshold of Thiol-Based Monolayer on Copper: Effect of Electric Potential and Elevated Temperature. Electrochim. Acta 2016, 198, 185-194. [CrossRef]

208. Zaba, T.; Noworolska, A.; Bowers, C.M.; Breiten, B.; Whitesides, G.M.; Cyganik, P. Formation of Highly Ordered Self-Assembled Monolayers of Alkynes on Au(111) Substrate. J. Am. Chem. Soc. 2014, 136, 11918-11921. [CrossRef]

209. Widawsky, J.R.; Chen, W.; Vázquez, H.; Kim, T.; Breslow, R.; Hybertsen, M.S.; Venkataraman, L. Length-Dependent Thermopower of Highly Conducting Au-C Bonded Single Molecule Junctions. Nano Lett. 2013, 13, 2889-2894. [CrossRef] [PubMed]

210. Chen, W.; Widawsky, J.R.; Vázquez, H.; Schneebeli, S.T.; Hybertsen, M.S.; Breslow, R.; Venkataraman, L. Highly Conducting $\pi$-Conjugated Molecular Junctions Covalently Bonded to Gold Electrodes. J. Am. Chem. Soc. 2011, 133, 17160-17163. [CrossRef] [PubMed]

211. Hong, W.; Li, H.; Liu, S.-X.; Fu, Y.; Li, J.; Kaliginedi, V.; Decurtins, S.; Wandlowski, T. Trimethylsilyl-Terminated Oligo(Phenylene Ethynylene)s: An Approach to Single-Molecule Junctions with Covalent Au-C o-Bonds. J. Am. Chem. Soc. 2012, 134, 19425-19431. [CrossRef] [PubMed] 
212. Fu, Y.; Chen, S.; Kuzume, A.; Rudnev, A.; Huang, C.; Kaliginedi, V.; Baghernejad, M.; Hong, W.; Wandlowski, T.; Decurtins, S.; et al. Exploitation of Desilylation Chemistry in Tailor-Made Functionalization on Diverse Surfaces. Nat. Commun. 2015, 6, 6403. [CrossRef]

213. Crudden, C.M.; Horton, J.H.; Ebralidze, I.I.; Zenkina, O.V.; McLean, A.B.; Drevniok, B.; She, Z.; Kraatz, H.-B.; Mosey, N.J.; Seki, T.; et al. Ultra Stable Self-Assembled Monolayers of N-Heterocyclic Carbenes on Gold. Nat. Chem. 2014, 6, 409-414. [CrossRef]

214. Zhao, J.; Davis, J.J. Force Dependent Metalloprotein Conductance by Conducting Atomic Force Microscopy. Nanotechnology 2003, 14, 1023-1028. [CrossRef]

215. Frascerra, V.; Calabi, F.; Maruccio, G.; Pompa, P.P.; Cingolani, R.; Rinaldi, R. Resonant Electron Tunneling through Azurin in Air and Liquid by Scanning Tunneling Microscopy. IEEE Trans. Nanotechnol. 2005, 4, 637-640. [CrossRef]

216. Artés, J.M.; López-Martínez, M.; Giraudet, A.; Díez-Pérez, I.; Sanz, F.; Gorostiza, P. Current-Voltage Characteristics and Transition Voltage Spectroscopy of Individual Redox Proteins. J. Am. Chem. Soc. 2012, 134, 20218-20221. [CrossRef]

217. Bâldea, I. Important Insight into Electron Transfer in Single-Molecule Junctions Based on Redox Metalloproteins from Transition Voltage Spectroscopy. J. Phys. Chem. C 2013, 117, 25798-25804. [CrossRef]

218. Ruiz, M.P.; Aragonès, A.C.; Camarero, N.; Vilhena, J.G.; Ortega, M.; Zotti, L.A.; Pérez, R.; Cuevas, J.C.; Gorostiza, P.; Díez-Pérez, I. Bioengineering a Single-Protein Junction. J. Am. Chem. Soc. 2017, 139, 15337-15346. [CrossRef] [PubMed]

219. Sagara, T.; Nakajima, S.; Akutsu, H.; Niki, K.; Wilson, G.S. Heterogeneous Electron-Transfer Rate Measurements of Cytochrome C3 at Mercury Electrodes. J. Electroanal. Chem. Interfacial Electrochem. 1991, 297, 271-282. [CrossRef]

220. Ron, I.; Sepunaru, L.; Itzhakov, S.; Belenkova, T.; Friedman, N.; Pecht, I.; Sheves, M.; Cahen, D. Proteins as Electronic Materials: Electron Transport through Solid-State Protein Monolayer Junctions. J. Am. Chem. Soc. 2010, 132, 4131-4140. [CrossRef] [PubMed]

221. Sepunaru, L.; Pecht, I.; Sheves, M.; Cahen, D. Solid-State Electron Transport across Azurin: From a Temperature-Independent to a Temperature-Activated Mechanism. J. Am. Chem. Soc. 2011, 133, 2421-2423. [CrossRef] [PubMed]

222. Amdursky, N.; Marchak, D.; Sepunaru, L.; Pecht, I.; Sheves, M.; Cahen, D. Electronic Transport via Proteins. Adv. Mater. 2014, 26, 7142-7161. [CrossRef]

223. Valianti, S.; Cuevas, J.C.; Skourtis, S.S. Charge-Transport Mechanisms in Azurin-Based Monolayer Junctions. J. Phys. Chem. C 2019, 123, 5907-5922. [CrossRef]

224. Beratan, D.N.; Skourtis, S.S.; Balabin, I.A.; Balaeff, A.; Keinan, S.; Venkatramani, R.; Xiao, D. Steering Electrons on Moving Pathways. Acc. Chem. Res. 2009, 42, 1669-1678. [CrossRef]

225. Skourtis, S.S.; Waldeck, D.H.; Beratan, D.N. Fluctuations in Biological and Bioinspired Electron-Transfer Reactions. Annu. Rev. Phys. Chem. 2010, 61, 461-485. [CrossRef]

226. May, V.; Kühn, O. Charge and Energy Transfer Dynamics in Molecular Systems; Wiley-VCH Verlag GmbH \& Co. KgaA: Weinheim, Germany, 2011.

227. Winkler, J.R.; Gray, H.B. Electron Flow through Metalloproteins. Chem. Rev. 2014, 114, 3369-3380. [CrossRef]

228. Beratan, D.N.; Liu, C.; Migliore, A.; Polizzi, N.F.; Skourtis, S.S.; Zhang, P.; Zhang, Y. Charge Transfer in Dynamical Biosystems, or The Treachery of (Static) Images. Acc. Chem. Res. 2015, 48, 474-481. [CrossRef] [PubMed]

229. Adams, E.M.; Lampret, O.; König, B.; Happe, T.; Havenith, M. Solvent Dynamics Play a Decisive Role in the Complex Formation of Biologically Relevant Redox Proteins. Phys. Chem. Chem. Phys. 2020, 22, 7451-7459. [CrossRef] [PubMed]

230. Venkat, A.S.; Corni, S.; Di Felice, R. Electronic Coupling Between Azurin and Gold at Different Protein/Substrate Orientations. Small 2007, 3, 1431-1437. [CrossRef] [PubMed]

231. Castañeda Ocampo, O.E.; Gordiichuk, P.; Catarci, S.; Gautier, D.A.; Herrmann, A.; Chiechi, R.C. Mechanism of Orientation-Dependent Asymmetric Charge Transport in Tunneling Junctions Comprising Photosystem I. J. Am. Chem. Soc. 2015, 137, 8419-8427. [CrossRef] [PubMed]

232. Amdursky, N.; Ferber, D.; Bortolotti, C.A.; Dolgikh, D.A.; Chertkova, R.V.; Pecht, I.; Sheves, M.; Cahen, D. Solid-State Electron Transport via Cytochrome c Depends on Electronic Coupling to Electrodes and across the Protein. Proc. Natl. Acad. Sci. USA 2014, 111, 5556-5561. [CrossRef] 
233. Seeman, N.C. DNA in a Material World. Nature 2003, 421, 427-431. [CrossRef]

234. LaBean, T.H.; Li, H. Constructing Novel Materials with DNA. Nano Today 2007, 2, 26-35. [CrossRef]

235. Linko, V.; Paasonen, S.T.; Kuzyk, A.; Törmä, P.; Toppari, J.J. Characterization of the Conductance Mechanisms of DNA Origami by AC Ompedance Spectroscopy. Small 2009, 5, 2382-2386. [CrossRef] [PubMed]

236. Tuukkanen, S.; Toppari, J.J.; Hytönen, V.P.; Kuzyk, A.; Kulomaa, M.S.; Törmä, P. Dielectrophoresis as a Tool for Nanoscale DNA Manipulation. Int. J. Nanotechnol. 2005, 2, 280-291. [CrossRef]

237. Liu, Y.; Chung, J.H.; Liu, W.K.; Ruoff, R.S. Dielectrophoretic Assembly of Nanowires. J. Phys. Chem. B 2006, 110, 14098-14106. [CrossRef] [PubMed]

238. Krupke, R.; Hennrich, F.; Kappes, M.M.; Löhneysen, H.V. Surface Conductance Induced Dielectrophoresis of Semiconducting Single-Walled Carbon Nanotubes. Nano Lett. 2004, 4, 1395-1399. [CrossRef]

239. Vijayaraghavan, A.; Sciascia, C.; Dehm, S.; Lombardo, A.; Bonetti, A.; Ferrari, A.C.; Krupke, R. Dielectrophoretic Assembly of High-Density Arrays of Individual Graphene Devices for Rapid Screening. ACS Nano 2009, 3, 1729-1734. [CrossRef] [PubMed]

240. Freer, E.M.; Grachev, O.; Duan, X.; Martin, S.; Stumbo, D.P. High-Yield Self-Limiting Single-Nanowire Assembly with Dielectrophoresis. Nat. Nanotechnol. 2010, 5, 525-530. [CrossRef] [PubMed]

241. Schukfeh, M.I.; Sepunaru, L.; Behr, P.; Li, W.; Pecht, I.; Sheves, M.; Cahen, D.; Tornow, M. Towards Nanometer-Spaced Silicon Contacts to Proteins. Nanotechnology 2016, 27, 115302. [CrossRef] [PubMed]

242. Barik, A.; Zhang, Y.; Grassi, R.; Nadappuram, B.P.; Edel, J.B.; Low, T.; Koester, S.J.; Oh, S.-H.H. Graphene-Edge Dielectrophoretic Tweezers for Trapping of Biomolecules. Nature 2017, 8, 1867. [CrossRef]

243. He, X.; Tang, J.; Hu, H.; Shi, J.; Guan, Z.; Zhang, S.; Xu, H. Electrically Driven Optical Antennas Based on Template Dielectrophoretic Trapping. ACS Nano 2019, 13, 14041-14047. [CrossRef]

244. Hughes, M.P. AC Electrokinetics: Applications for Nanotechnology. Nanotechnology 2000, 11, 124-132. [CrossRef]

245. Pethig, R. Review Article-Dielectrophoresis: Status of the Theory, Technology, and Applications. Biomicrofluidics 2010, 4, 22811. [CrossRef]

246. Jones, T.B. Basic Theory of Dielectrophoresis and Electrorotation. IEEE Eng. Med. Biol. Mag. 2003, 22, 33-42. [CrossRef]

247. Castellanos, A.; Ramos, A.; González, A.; Green, N.G.; Morgan, H. Electrohydrodynamics and Dielectrophoresis in Microsystems: Scaling Laws. J. Phys. D Appl. Phys. 2003, 36, 2584-2597. [CrossRef]

248. Burke, P.J. Nanodielectrophoresis: Electronic Nanotweezers. In Encyclopedia of Nanoscience and Nanotechnology; Nalwa, H.S., Ed.; American Scientific Publishers: Valencia, CA, USA, 2003; pp. 1-19.

249. Lapizco-Encinas, B.H.; Rito-Palomares, M. Dielectrophoresis for the Manipulation of Nanobioparticles. Electrophoresis 2007, 28, 4521-4538. [CrossRef]

250. Zhang, C.; Khoshmanesh, K.; Mitchell, A.; Kalantar-zadeh, K. Dielectrophoresis for Manipulation of Micro/Nano Particles in Microfluidic Systems. Anal. Bioanal. Chem. 2010, 396, 401-420. [CrossRef] [PubMed]

251. Meighan, M.M.; Staton, S.J.R.; Hayes, M.A. Bioanalytical Separations Using Electric Field Gradient Techniques. Electrophoresis 2009, 30, 852-865. [CrossRef] [PubMed]

252. Kuzyk, A. Dielectrophoresis at the Nanoscale. Electrophoresis 2011, 32, 2307-2313. [CrossRef] [PubMed]

253. Ismael, A.; Wang, X.; Bennett, T.L.R.; Wilkinson, L.A.; Robinson, B.J.; Long, N.J.; Cohen, F.; Lambert, C.J. Tuning the Thermoelectrical Properties of Anthracene-Based Self-Assembled Monolayers. Chem. Sci. 2020, 11, 6836-6841. [CrossRef]

254. Wang, X.; Bennett, T.L.R.; Ismael, A.; Wilkinson, L.A.; Hamill, J.; White, A.J.P.; Grace, I.M.; Kolosov, O.V.; Albrecht, T.; Robinson, B.J.; et al. Scale-up of Room-Temperature Constructive Quantum Interference from Single Molecules to Self-Assembled Molecular-Electronic Films. J. Am. Chem. Soc. 2020, 142, 8555-8560. [CrossRef] [PubMed]

255. Xing, L.; Peng, Z.; Li, W.; Wu, K. On Controllability and Applicability of Surface Molecular Self-Assemblies. Acc. Chem. Res. 2019, 52, 1048-1058. [CrossRef]

256. Nickmans, K.; Schenning, A.P.H.J. Directed Self-Assembly of Liquid-Crystalline Molecular Building Blocks for Sub-5 Nm Nanopatterning. Adv. Mater. 2018, 30, 1703713. [CrossRef]

257. Bolu, B.S.; Sanyal, R.; Sanyal, A. Drug Delivery Systems from Self-Assembly of Dendron-Polymer Conjugates. Molecules 2018, 23, 1570. [CrossRef] 
258. Song, Z.; Chen, X.; You, X.; Huang, K.; Dhinakar, A.; Gu, Z.; Wu, J. Self-Assembly of Peptide Amphiphiles for Drug Delivery: The Role of Peptide Primary and Secondary Structures. Biomater. Sci. 2017, 5, 2369-2380. [CrossRef]

259. Galeotti, F.; Pisco, M.; Cusano, A. Self-Assembly on Optical Fibers: A Powerful Nanofabrication Tool for next Generation "Lab-on-Fiber" Optrodes. Nanoscale 2018, 10, 22673-22700. [CrossRef] [PubMed]

260. Zhang, X.; Parekh, G.; Guo, B.; Huang, X.; Dong, Y.; Han, W.; Chen, X.; Xiao, G. Polyphenol and Self-Assembly: Metal Polyphenol Nanonetwork for Drug Delivery and Pharmaceutical Applications. Future Drug Discov. 2019, 1, FDD7. [CrossRef]

261. Hussain, S.A.; Dey, B.; Bhattacharjee, D.; Mehta, N. Unique Supramolecular Assembly through Langmuir-Blodgett (LB) Technique. Heliyon 2018, 4, e01038. [CrossRef] [PubMed]

262. Moehwald, H.; Brezesinski, G. From Langmuir Monolayers to Multilayer Films. Langmuir 2016, 32, 10445-10458. [CrossRef]

263. Dopierała, K.; Rojewska, M.; Skrzypiec, M.; Dutkiewicz, M.; Maciejewski, H.; Prochaska, K. Preparation and Characterisation of Monolayers and Langmuir-Blodgett Films of Liquid Crystal Mixed with Cubic Silsesquioxanes. Liq. Cryst. 2017, 45, 351-361. [CrossRef]

264. Pradilla, D.; Simon, S.; Sjöblom, J.; Samaniuk, J.; Skrzypiec, M.; Vermant, J. Sorption and Interfacial Rheology Study of Model Asphaltene Compounds. Langmuir 2016, 32, 2900-2911. [CrossRef]

265. Ma, Y.; Xie, Y.; Lin, L.; Zhang, L.; Liu, M.; Guo, Y.; Lan, Z.; Lu, Z. Photodimerization Kinetics of a Styrylquinoline Derivative in Langmuir-Blodgett Monolayers Monitored by Second Harmonic Generation. J. Phys. Chem. C 2017, 121, 23541-23550. [CrossRef]

266. Wang, Z.; Si, J.; Song, Z.; Zhang, P.; Wang, J.; Hao, Y.; Li, W.; Zhang, P.; Miao, S. Precise and Instrumental Measurement of Thermodynamics and Kinetics of Froth Flotation by Langmuir-Blodgett Technique. Colloids Surf. A Physicochem. Eng. Asp. 2020, 605, 125337. [CrossRef]

267. Da, C.; Junior, R.; Caseli, L. Adsorption and Enzyme Activity of Asparaginase at Lipid Langmuir and Langmuir-Blodgett Films. Mater. Sci. Eng. C 2017, 73, 579-584.

268. Brand, I.; Juhaniewicz-Debinska, J.; Wickramasinghe, L.; Verani, C.N. An in Situ Spectroelectrochemical Study on the Orientation Changes of an [FeIIILN2O3] Metallosurfactant Deposited as LB Films on Gold Electrode Surfaces. Dalton Trans. 2018, 47, 14218-14226. [CrossRef]

269. Su, Z.; Shodiev, M.; Leitch, J.J.; Abbasi, F.; Lipkowski, J. In Situ Electrochemical and PM-IRRAS Studies of Alamethicin Ion Channel Formation in Model Phospholipid Bilayers. J. Electroanal. Chem. 2018, 819, 251-259. [CrossRef]

270. Cea, P.; Martín, S.; Villares, A.; Möbius, D.; Carmen López, M. Use of UV-Vis Reflection Spectroscopy for Determining the Organization of Viologen and Viologen Tetracyanoquinodimethanide Monolayers. J. Phys. Chem. B 2006, 110, 963-970. [CrossRef] [PubMed]

271. Ariga, K.; Yamauchi, Y.; Mori, T.; Hill, J.P. 25th Anniversary Article: What Can Be Done with the Langmuir-Blodgett Method? Recent Developments and Its Critical Role in Materials Science. Adv. Mater. 2013, 25, 6477-6512. [CrossRef] [PubMed]

272. Hussain, S.A.; Bhattacharjee, D. Langmuir Blodgett Films and Molecular Electronics. Mod. Phys. Lett. B 2009, 23, 3437-3451. [CrossRef]

273. Hirahara, M.; Kaida, H.; Miyauchi, Y.; Goto, H.; Yamagishi, A.; Umemura, Y. Application of Electrospray Spreading to a Modified Langmuir-Blodgett Technique for Organo-Clay Hybrid Film Preparation. Colloids Surf. A 2019, 580, 123714. [CrossRef]

274. Giner-casares, J.J.; Brezesinski, G.; Möhwald, H. Current Opinion in Colloid \& Interface Science Langmuir Monolayers as Unique Physical Models. Curr. Opin. Colloid Interface Sci. 2014, 19, 176-182.

275. Gyepi-Garbrah, S.H.; Silerová, R. The First Direct Comparison of Self-Assembly and Langmuir-Blodgett Deposition Techniques: Two Routes to Highly Organized Monolayers. Phys. Chem. Chem. Phys. 2002, 4, 3436-3442. [CrossRef]

276. Villares, A.; Lydon, D.P.; Low, P.J.; Robinson, B.J.; Ashwell, G.J.; Royo, F.M.; Cea, P. Characterization and Conductivity of Langmuir-Blodgett Films Prepared from an Amine-Substituted Oligo (Phenylene Ethynylene). Chem Mater. 2008, 20, 258-264. [CrossRef]

277. Martín, S.; Pera, G.; Ballesteros, L.M.; Hope, A.J.; Marqués-González, S.; Low, P.J.; Pérez-Murano, F.; Nichols, R.J.; Cea, P. Towards the Fabrication of the Top-Contact Electrode in Molecular Junctions by Photoreduction of a Metal Precursor. Chem. Eur. J. 2014, 20, 3421-3426. [CrossRef] 
278. Haro, M.; Giner, B.; Gascón, I.; Royo, F.M.; López, M.C. Isomerization Behavior of an Azopolymer in Terms of the Langmuir-Blodgett Film Thickness and the Transference Surface Pressure. Macromolecules 2007, 40, 2058-2069. [CrossRef]

279. Haro, M.; Gascón, I.; Aroca, R.; López, M.C.; Royo, F.M. Structural Characterization and Properties of an Azopolymer Arranged in Langmuir and Langmuir-Blodgett Films. J. Colloid Interface Sci. 2008, 319, 277-286. [CrossRef] [PubMed]

280. Jayamurugan, G.; Gowri, V.; Hernández, D.; Martin, S.; González-Orive, A.; Dengiz, C.; Dumele, O.; Pérez-Murano, F.; Gisselbrecht, J.P.; Boudon, C.; et al. Design and Synthesis of Aviram-Ratner-Type Dyads and Rectification Studies in Langmuir-Blodgett (LB) Films. Chem. Eur. J. 2016, 22, 10539-10547. [CrossRef]

281. Kausar, A. Survey on Langmuir-Blodgett Films of Polymer and Polymeric Composite. Polym. Plast. Technol. Eng. 2018, 56, 932-945. [CrossRef]

282. Silva, E.A.; Gregori, A.; Fernandes, J.D.; Njel, C.; DedryvèreDedryvère, R.; L Constantino, C.J.; Hiorns, R.C.; Lartigau-Dagron, C.; Olivati, C.A. Understanding the Langmuir and Langmuir-Schaefer Film Conformation of Low-Bandgap Polymers and Their Bulk Heterojunctions with PCBM. Nanotechnology 2020, 31, 315712-315726. [CrossRef] [PubMed]

283. Yamamoto, S.; Nishina, N.; Matsui, J.; Miyashita, T.; Mitsuishi, M. High-Density and Monolayer-Level Integration of $\pi$-Conjugated Units: Amphiphilic Carbazole Homopolymer Langmuir-Blodgett Films. Langmuir 2018, 34, 10491-10497. [CrossRef] [PubMed]

284. Dey, B.; Chakraborty, S.; Chakraborty, S.; Bhattacharjee, D.; Khan, A.; Arshad Hussain, S. Electrical Switching Behaviour of a Metalloporphyrin in Langmuir-Blodgett Film. Org. Electron. 2018, 55, 50-62. [CrossRef]

285. Nizioł, J.; Makyła-Juzak, K.; Radko, A.; Ekiert, R.; Zemła, J.; Górska, N.; Chachaj-Brekiesz, A.; Marzec, M.; Harańczyk, H.; Dynarowicz-Latka, P. Linear, Self-Assembled Patterns Appearing Spontaneously as a Result of DNA-CTMA Lipoplex Langmuir-Blodgett Deposition on a Solid Surface. Polymer 2019, 178, 121643. [CrossRef]

286. Makowiecki, J.; Piosik, E.; Neunert, G.; Stolarski, R.; Piecek, W.; Martynski, T. Molecular Organization of Perylene Derivatives in Langmuir-Blodgett Multilayers. Opt. Mater. 2015, 46, 555-560. [CrossRef]

287. Diego Fernandes, J.; Maximino, M.D.; Braunger, M.L.; Pereira, M.S.; de Almeida Olivati, C.; Constantino, C.J.L.; Alessio, P. Supramolecular Architecture and Electrical Conductivity in Organic Semiconducting Thin Films. Phys. Chem. Chem. Phys. 2020, 22, 13554-13562. [CrossRef]

288. Cavazzini Cesca, E.; Maria Hoffmeister, D.; Naidek, K.P.; Batista Marques Novo, A.; Serbena, J.P.; Hümmelgen, I.A.; Westphal, E.; Araki, K.; Toma, H.E.; Winnischofer, H. 1,3,4-Oxadiazole Based Ruthenium Amphiphile for Langmuir-Blodgett Films and Photo-Responsive Logic Gate Construction. Electrochim. Acta 2020, 350, 136350. [CrossRef]

289. Ohashi, T.; Kikuchi, N.; Fujimori, A. Creation of Highly Ordered “Nano-Mille-Feuille” Hard/Soft Nanoparticle Multilayers with Interparticle Cross-Linking by Diacetylene-Containing Chains. Langmuir 2020, 36, 5596-5607. [CrossRef] [PubMed]

290. Kursunlu, A.N.; Acikbas, Y.; Ozmen, M.; Erdogan, M.; Capan, R. Fabrication of LB Thin Film of Pillar[5]Arene-2-Amino-3-Hydroxypyridine for the Sensing of Vapors. Mater. Lett. 2020, 267, 127538. [CrossRef]

291. Liu, H.; Siron, M.; Gao, M.; Lu, D.; Bekenstein, Y.; Zhang, D.; Dou, L.; Alivisatos, A.P.; Yang, P. Lead Halide Perovskite Nanowires Stabilized by Block Copolymers for Langmuir-Blodgett Assembly. Nano Res. 2020, 13, 1453-1458. [CrossRef]

292. Su, L.; Xu, F.; Chen, J.; Cao, Y.; Wang, C. Photoresponsive 2D Polymeric Langmuir-Blodgett Films of 2,3,6,7,10,11-Hexaiminotriphenylene. New J. Chem. 2020, 44, 5656-5660. [CrossRef]

293. Ariga, K.; Ji, Q.; Nakanishi, W.; Hill, J.P.; Aono, M. Nanoarchitectonics: A New Materials Horizon for Nanotechnology. Mater. Horiz. 2015, 2, 406-413. [CrossRef]

294. Ariga, K.; Yamauchi, Y. Nanoarchitectonics from Atom to Life. Chem. Asian J. 2020, 15, 718-728. [CrossRef]

295. Ariga, K. Don't Forget Langmuir-Blodgett Films 2020: Interfacial Nanoarchitectonics with Molecules, Materials, and Living Objects. Langmuir 2020, 36, 7158-7180. [CrossRef]

296. Ariga, K.; Mori, T.; Li, J. Langmuir Nanoarchitectonics from Basic to Frontier. Langmuir 2019, 35, 3585-3599. [CrossRef]

297. Govindaraju, T.; Avinash, M.B. Two-Dimensional Nanoarchitectonics: Organic and Hybrid Materials. Nanoscale 2012, 4, 6102-6117. [CrossRef] 
298. Ramanathan, M.; Shrestha, L.K.; Mori, T.; Ji, Q.; Hill, J.P.; Ariga, K. Amphiphile Nanoarchitectonics: From Basic Physical Chemistry to Advanced Applications. Phys. Chem. Chem. Phys. 2013, 15, 10580-10611. [CrossRef]

299. Ariga, K.; Mori, T.; Kitao, T.; Uemura, T. Supramolecular Chiral Nanoarchitectonics. Adv. Mater. 2020, 2020, 1905657. [CrossRef] [PubMed]

300. Komiyama, M.; Mori, T.; Ariga, K. Molecular Imprinting: Materials Nanoarchitectonics with Molecular Information. Bull. Chem. Soc. Jpn. 2018, 91, 1075-1111. [CrossRef]

301. Liu, J.; Zhou, H.; Yang, W.; Ariga, K. Soft Nanoarchitectonics for Enantioselective Biosensing. Acc. Chem. Res. 2020, 53, 644-653. [CrossRef] [PubMed]

302. Abe, H.; Liu, J.; Ariga, K. Catalytic Nanoarchitectonics for Environmentally Compatible Energy Generation. Mater. Today 2016, 19, 12-18. [CrossRef]

303. Komiyama, M.; Ariga, K. Nanoarchitectonics to Prepare Practically Useful Artificial Enzymes. Mol. Catal. 2019, 475, 110492. [CrossRef]

304. Ariga, K.; Ji, Q.; Mori, T.; Naito, M.; Yamauchi, Y.; Abe, H.; Hill, J.P. Enzyme Nanoarchitectonics: Organization and Device Application. Chem. Soc. Rev. 2013, 42, 6322-6345. [CrossRef]

305. Ariga, K.; Ito, M.; Mori, T.; Watanabe, S.; Takeya, J. Atom/Molecular Nanoarchitectonics for Devices and Related Applications. Nano Today 2019, 28, 100762. [CrossRef]

306. Xu, J.; Zhang, J.; Zhang, W.; Lee, C.S. Interlayer Nanoarchitectonics of Two-Dimensional Transition-Metal Dichalcogenides Nanosheets for Energy Storage and Conversion Applications. Adv. Energy Mater. 2017, 7, 1700571. [CrossRef]

307. Nakanishi, W.; Minami, K.; Shrestha, L.K.; Ji, Q.; Hill, J.P.; Ariga, K. Bioactive Nanocarbon Assemblies: Nanoarchitectonics and Applications. Nano Today 2014, 9, 378-394. [CrossRef]

308. Ariga, K.; Leong, D.T.; Mori, T. Nanoarchitectonics for Hybrid and Related Materials for Bio-Oriented Applications. Adv. Funct. Mater. 2018, 28, 1702905. [CrossRef]

309. Liang, X.; Li, L.; Tang, J.; Komiyama, M.; Ariga, K. Dynamism of Supramolecular DNA/RNA Nanoarchitectonics: From Interlocked Structures to Molecular Machines. Bull. Chem. Soc. Jpn. 2020, 93, 581-603. [CrossRef]

310. Chiodini, S.; Ruiz-Rincón, S.; Garcia, P.D.; Martin, S.; Kettelhoit, K.; Armenia, I.; Werz, D.B.; Cea, P. Bottom Effect in Atomic Force Microscopy Nanomechanics. Small 2020, 2020, 2000269. [CrossRef]

311. Rauf, S.; Vijjapu, M.T.; Andrés, M.A.; Gascón, I.; Roubeau, O.; Eddaoudi, M.; Salama, K.N. Highly Selective Metal-Organic Framework Textile Humidity Sensor. ACS Appl. Mater. Interfaces 2020, 12, 29999-30006. [CrossRef] [PubMed]

312. Bélanger, D.; Pinson, J. Electrografting: A Powerful Method for Surface Modification. Chem. Soc. Rev. 2011, 40, 3995-4048. [CrossRef] [PubMed]

313. Li, W.; Liu, Q.; Zhang, Y.; Li, C.; He, Z.; Choy, W.C.H.; Low, P.J.; Sonar, P.; Kyaw, A.K.K. Biodegradable Materials and Green Processing for Green Electronics. Adv. Mater. 2020, 2020, 2001591. [CrossRef]

314. Hapiot, P.; Lagrost, C.; Leroux, Y.R. Molecular Nano-Structuration of Carbon Surfaces through Reductive Diazonium Salts Grafting. Curr. Opin. Electrochem. 2018, 7, 103-108. [CrossRef]

315. Pinson, J.; Podvorica, F.I. Surface Modification of Materials: Electrografting of Organic Films. Curr. Opin. Electrochem. 2020, 24, 44-48. [CrossRef]

316. Delamar, M.; Hitmi, R.; Pinson, J.; Savéant, J. Covalent Modification of Carbon Surfaces by Grafting of Functionalized Aryl Radicals Produced from Electrochemical Reduction of Diazonium Salts. J. Am. Chem. Soc. 1992, 114, 5883-5884. [CrossRef]

317. Anex, C.; Touzé, E.; Curet, L.; Gohier, F.; Cougnon, C. Base-Assisted Electrografting of Aromatic Amines. ChemElectroChem 2019, 6, 4963-4969. [CrossRef]

318. Mccreery, R.L. The Merger of Electrochemistry and Molecular Electronics. Chem. Rec. 2012, 12, 149-163. [CrossRef]

319. Christophe Lacroix, J. Electrochemistry Does the Impossible: Robust and Reliable Large Area Molecular Junctions. Curr. Opin. Electrochem. 2018, 7, 153-160. [CrossRef]

320. Randriamahazaka, H.; Ghilane, J. Electrografting and Controlled Surface Functionalization of Carbon Based Surfaces for Electroanalysis. Electroanalysis 2016, 28, 13-26. [CrossRef]

321. Yan, H.; Bergren, A.J.; McCreery, R.L. All-Carbon Molecular Tunnel Junctions. J. Am. Chem. Soc. 2011, 133, 19168-19177. [CrossRef] [PubMed]

322. McCreery, R.; Bergren, A.; Morteza-Najarian, A.; Sayed, S.Y.; Yan, H. Electron Transport in All-Carbon Molecular Electronic Devices. Faraday Discuss. 2014, 172, 9-25. [CrossRef] [PubMed] 
323. Sayed, S.Y.; Bayat, A.; Kondratenko, M.; Leroux, Y.; Hapiot, P.; McCreery, R.L. Bilayer Molecular Electronics: All-Carbon Electronic Junctions Containing Molecular Bilayers Made with "Click" Chemistry. J. Am. Chem. Soc. 2013, 135, 12972-12975. [CrossRef] [PubMed]

324. Guselnikova, O.; Miliutina, E.; Elashnikov, R.; Burtsev, V.; Chehimi, M.M.; Svorcik, V.; Yusubov, M.; Lyutakov, O.; Postnikov, P. Chemical Modification of Gold Surface via UV-Generated Aryl Radicals Derived 3,5-Bis(Trifluoromethyl)Phenyl)Iodonium Salt. Prog. Org. Coat. 2019, 136, 105211. [CrossRef]

325. Ramírez-Chan, D.E.; Fragoso-Soriano, R.; González, F.J. Effect of Electrolyte Ions on the Formation, Electroactivity, and Rectification Properties of Films Obtained by Electrografting. ChemElectroChem 2020, 7 , 904-913. [CrossRef]

326. Madsen, M.R.; Koefoed, L.; Jensen, H.; Daasbjerg, K.; Pedersen, S.U. Two-Phase Bipolar Electrografting. Electrochim. Acta 2019, 317, 61-69. [CrossRef]

327. Arrotin, B.; Noël, J.M.; Delhalle, J.; Mespouille, L.; Mekhalif, Z. Electrografting of Mixed Organophosphonic Monolayers for SI-ATRP of 2-Methacryloyloxyethyl Phosphorylcholine. J. Coat. Technol. Res. 2019, 16, 1121-1132. [CrossRef]

328. Guo, D.; Wang, L.; Wang, X.; Xiao, Y.; Wang, C.; Chen, L.; Ding, Y. PEDOT Coating Enhanced Electromechanical Performances and Prolonged Stable Working Time of IPMC Actuator. Sens. Actuators B Chem. 2020, 305, 127488. [CrossRef]

329. Villemin, E.; Lemarque, B.; Thiêt Vũ, T.; Nguyen, V.Q.; Trippé-Allard, G.; Martin, P.; Lacaze, P.-C.; Lacroix, J.-C. Improved Adhesion of Poly(3,4-Ethylenedioxythiophene) (PEDOT) Thin Film to Solid Substrates Using Electrografted Promoters and Application to Efficient Nanoplasmonic Devices. Synth. Met. 2019, 248, 45-52. [CrossRef]

330. Gutiérrez-Sánchez, C.; Mediavilla, O.; Guerrero-Esteban, T.; Revenga-Parra, O.; Pariente, E.; On Lorenzo, E. Direct Covalent Immobilization of New Nitrogen-Doped Carbon Nanodots by Electrografting for Sensing Applications. Carbon 2020, 159, 303-310. [CrossRef]

331. Berg, K.E.; Leroux, Y.R.; Hapiot, P.; Henry, C.S. Increasing Applications of Graphite Thermoplastic Electrodes with Aryl Diazonium Grafting. ChemElectroChem 2019, 6, 4811-4816. [CrossRef]

332. Aceta, Y.; Leroux, Y.R.; Hapiot, P. Evaluation of Alkyl-Ferrocene Monolayers on Carbons for Charge Storage Applications, a Voltammetry and Impedance Spectroscopy Investigation. ChemElectroChem 2019, 6, 1704-1710. [CrossRef]

333. Wu, T.; Lankshear, E.R.; Downard, A.J. Simultaneous Electro-Click and Electrochemically Mediated Polymerization Reactions for One-Pot Grafting from a Controlled Density of Anchor Sites. ChemElectroChem 2019, 6, 5149-5154. [CrossRef]

334. Gabaji, M.; Médard, J.M.; Hemmerle, A.; Pinson, J.; Michel, J.P. From Langmuir-Blodgett to Grafted Films. Langmuir 2020, 36, 2534-2542. [CrossRef]

335. Dalla Francesca, K.; Salhani, C.; Timpa, S.; Rastikian, J.; Suffit, S.; Martin, P.; Lacroix, J.; Lafarge, P.; Barraud, C.; Della Rocca, M.L. Large-Area in Plane Molecular Junctions by Electrografting in $10 \mathrm{Nm}$ Metallic Nanotrenches. AIP Adv. 2020, 10, 25023. [CrossRef]

336. Nguyen, H.H.; Park, J.; Kang, S.; Kim, M. Surface Plasmon Resonance: A Versatile Technique for Biosensor Applications. Sensors 2015, 15, 10481-10510. [CrossRef]

337. Fioresi, F.; Rouleau, A.; Maximova, K.; Vieillard, J.; Boireau, W.; Caille, C.E.; Soulignac, C.; Zeggari, R.; Clamens, T.; Lesouhaitier, O.; et al. Electrografting of Diazonium Salt for SPR Application. Mater. Today Proc. 2019, 6, 340-344. [CrossRef]

338. Koefoed, L.; Pedersen, S.U.; Daasbjerg, K. Bipolar Electrochemistry-A Wireless Approach for Electrode Reactions. Curr. Opin. Electrochem. 2017, 2, 13-17. [CrossRef]

339. Available online: http://www.cabot-corp.com (accessed on 14 August 2020).

340. Levesque, L.; Lawrence, M.F.; Bourguignon, B.; Leclerc, G. Drug Eluting Device for Treating Vascular Diseases. WO Patent WO 2002066092, 19 August 2020.

341. Nichols, R.J.; Haiss, W.; Higgins, S.J.; Leary, E.; Martin, S.; Bethell, D. The Experimental Determination of the Conductance of Single Molecules. Phys. Chem. Chem. Phys. 2010, 12, 2801-2815. [CrossRef] [PubMed]

342. Walker, A.V. Building Robust and Reliable Molecular Constructs: Patterning, Metallic Contacts, and Layer-by-Layer Assembly. Langmuir 2010, 26, 13778-13785. [CrossRef] [PubMed] 
343. Wohlfart, P.; Weiß, J.; Käshammer, J.; Kreiter, M.; Winter, C.; Fischer, R.; Mittler-Neher, S. MOCVD of Aluminum Oxide/Hydroxide onto Organic Self-Assembled Monolayers. Chem. Vap. Depos. 1999, 5, 165-170. [CrossRef]

344. Haick, H.; Cahen, D. Contacting Organic Molecules by Soft Methods: Towards Molecule-Based Electronic Devices. Acc. Chem. Res. 2008, 41, 359-366. [CrossRef] [PubMed]

345. Hansen, C.R.; Sørensen, T.J.; Glyvradal, M.; Larsen, J.; Eisenhardt, S.H.; Bjørnholm, T.; Nielsen, M.M.; Feidenhans'l, R.; Laursen, B.W. Structure of the Buried Metal-Molecule Interface in Organic Thin Film Devices. Nano Lett. 2009, 9, 1052-1057. [CrossRef] [PubMed]

346. Haick, H.; Niitsoo, O.; Ghabboun, J.; Cahen, D. Electrical Contacts to Organic Molecular Films by Metal Evaporation: Effect of Contacting Details. J. Phys. Chem. C 2007, 111, 2318-2329. [CrossRef]

347. Haick, H.; Ambrico, M.; Ghabboun, J.; Ligonzo, T.; Cahen, D. Contacting Organic Molecules by Metal Evaporation. Phys. Chem. Chem. Phys. 2004, 6, 4538-4541. [CrossRef]

348. Xu, T.; Peterson, I.R.; Lakshmikantham, M.V.; Metzger, R.M. Rectification by a Monolayer of Hexadecylquinolinium Tricyanoquinodimethanide between Gold Electrodes. Angew. Chem. Int. Ed. 2001, 40, 1749-1752. [CrossRef]

349. Lodha, S.; Janes, D.B. Metal/Molecule/p-Type GaAs Heterostructure Devices. J. Appl. Phys. 2006, 100, 024503. [CrossRef]

350. Daniel, M.C.; Astruc, D. Gold Nanoparticles: Assembly, Supramolecular Chemistry, Quantum-Size-Related Properties, and Applications Toward Biology, Catalysis, and Nanotechnology. Chem. Rev. 2004, 104, 293-346. [CrossRef]

351. Sebastián, V.; Smith, C.D.; Jensen, K.F. Shape-Controlled Continuous Synthesis of Metal Nanostructures. Nanoscale 2016, 8, 7534-7543. [CrossRef] [PubMed]

352. Huang, X.; Tang, S.; Mu, X.; Dai, Y.; Chen, G.; Zhou, Z.; Ruan, F.; Yang, Z.; Zheng, N. Freestanding Palladium Nanosheets with Plasmonic and Catalytic Properties. Nat. Nanotechnol. 2011, 6, 28-32. [CrossRef] [PubMed]

353. Bonifas, A.P.; McCreery, R.L. 'Soft' $\mathrm{Au}, \mathrm{Pt}$ and $\mathrm{Cu}$ Contacts for Molecular Junctions through Surface-Diffusion-Mediated Deposition. Nat. Nanotechnol. 2010, 5, 612-617. [CrossRef] [PubMed]

354. Bonifas, A.P.; McCreery, R.L. Assembling Molecular Electronic Junctions One Molecule at a Time. Nano Lett. 2011, 11, 4725-4729. [CrossRef]

355. George, S.M. Atomic Layer Deposition: An Overview. Chem. Rev. 2010, 110, 111-131. [CrossRef]

356. Wu, J.Z.; Acharya, J.; Goul, R. In Vacuo Atomic Layer Deposition and Electron Tunneling Characterization of Ultrathin Dielectric Films for Metal/Insulator/Metal Tunnel Junctions. J. Vac. Sci. Technol. A 2020, 38, 040802. [CrossRef]

357. Seitz, O.; Dai, M.; Wallace, R.M.; Chabal, Y.J. Copper-Metal Deposition on Self Assembled Monolayer for Making Top Contacts in Molecular Electronic Devices. J. Am. Chem. Soc. 2009, 131, 18159-18167. [CrossRef]

358. Akkerman, H.B.; Blom, P.W.M.; De Leeuw, D.M.; De Boer, B. Towards Molecular Electronics with Large-Area Molecular Junctions. Nature 2006, 441, 69-72. [CrossRef]

359. Silien, C.; Buck, M. On the Role of Extrinsic and Intrinsic Defects in the Underpotential Deposition of Cu on Thiol-Modified Au(111) Electrodes. J. Phys. Chem. C 2008, 112, 3881-3890. [CrossRef]

360. Qu, D.; Uosaki, K. Formation of Continuous Platinum Layer on Top of an Organic Monolayer by Electrochemical Deposition Followed by Electroless Deposition. J. Electroanal. Chem. 2011, 662, 80-86. [CrossRef]

361. Eberle, F.; Saitner, M.; Boyen, H.G.; Kucera, J.; Gross, A.; Romanyuk, A.; Oelhafen, P.; D’Olieslaeger, M.; Manolova, M.; Kolb, D.M. A Molecular Double Decker: Extending the Limits of Current Metal-Molecule Hybrid Structures. Angew. Chem. Int. Ed. 2010, 49, 341-345. [CrossRef] [PubMed]

362. Eberle, F.; Metzler, M.; Kolb, D.M.; Saitner, M.; Wagner, P.; Boyen, H.G. Metallization of Ultra-Thin, Non-Thiol SAMs with Flat-Lying Molecular Units: Pd on 1, 4-Dicyanobenzene. ChemPhysChem 2010, 11, 2951-2956. [CrossRef] [PubMed]

363. Popoff, R.T.W.; Zavareh, A.A.; Kavanagh, K.L.; Yu, H.Z.; Popo, R.T.W.; Zavareh, A.A.; Kavanagh, K.L.; Yu, H.Z. Reduction of Gold Penetration through Phenyl-Terminated Alkyl Monolayers on Silicon. J. Phys. Chem. C 2012, 116, 17040-17047. [CrossRef]

364. Manolova, M.; Ivanova, V.; Kolb, D.M.; Boyen, H.G.; Ziemann, P.; Büttner, M.; Romanyuk, A.; Oelhafen, P. Metal Deposition onto Thiol-Covered Gold: Platinum on a 4-Mercaptopyridine SAM. Surf. Sci. 2005, 590, 146-153. [CrossRef] 
365. Manolova, M.; Kayser, M.; Kolb, D.M.; Boyen, H.G.; Ziemann, P.; Mayer, D.; Wirth, A. Rhodium Deposition onto a 4-Mercaptopyridine SAM on Au (111). Electrochim. Acta 2007, 52, 2740-2745. [CrossRef]

366. Schlesinger, M.; Paunovic, M. In Electrochemical Society Series; Wiley: New York, NY, USA, 2000.

367. Aldakov, D.; Bonnassieux, Y.; Geffroy, B.; Palacin, S. Selective Electroless Copper Deposition on Self-Assembled Dithiol Monolayers. ACS Appl. Mater. Interfaces 2009, 1, 584-589. [CrossRef]

368. Shi, Z.; Walker, A.V. Synthesis of Nickel Nanowires via Electroless Nanowire Deposition on Micropatterned Substrates. Langmuir 2011, 27, 11292-11295. [CrossRef]

369. Zangmeister, C.D.; Van Zee, R.D. Electroless Deposition of Copper onto 4-Mercaptobenzoic Acid Self-Assembled on Gold. Langmuir 2003, 19, 8065-8068. [CrossRef]

370. Lu, P.; Shi, Z.; Walker, A.V. Selective Electroless Deposition of Copper on Organic Thin Films with Improved Morphology. Langmuir 2011, 27, 13022-13028. [CrossRef]

371. Lu, P.; Walker, A.V. Investigation of the Mechanism of Electroless Deposition of Copper on Functionalized Alkanethiolate Self-Assembled Monolayers Adsorbed on Gold. Langmuir 2007, 23, 12577-12582. [CrossRef]

372. Loo, Y.L.; Lang, D.V.; Rogers, J.A.; Hsu, J.W.P. Electrical Contacts to Molecular Layers by Nanotransfer Printing. Nano Lett. 2003, 3, 913-917. [CrossRef]

373. Niskala, J.R.; Rice, W.C.; Bruce, R.C.; Merkel, T.J.; Tsui, F.; You, W. Tunneling Characteristics of Au-Alkanedithiol-Au Junctions Formed via Nanotransfer Printing (NTP). J. Am. Chem. Soc. 2012, 134, 12072-12082. [CrossRef] [PubMed]

374. Guerin, D.; Merckling, C.; Lenfant, S.; Wallart, X.; Pleutin, S.; Vuillaume, D. Silicon-Molecules-Metal Junctions by Transfer Printing: Chemical Synthesis and Electrical Properties. J. Phys. Chem. C 2007, 111, 7947-7956. [CrossRef]

375. Shimizu, K.T.; Fabbri, J.D.; Jelincic, J.J.; Melosh, N.A. Soft Deposition of Large-Area Metal Contacts for Molecular Electronics. Adv. Mater. 2006, 18, 1499-1504. [CrossRef]

376. Majumdar, N.; Gergel, N.; Routenberg, D.; Bean, J.C.; Harriott, L.R.; Li, B.; Pu, L.; Yao, Y.; Tour, J.M. Nanowell Device for the Electrical Characterization of Metal-Molecule-Metal Junctions. J. Vac. Sci. Technol. B Microelectron. Nanom. Struct. 2005, 23, 1417-1421. [CrossRef]

377. Chen, J.; Reed, M.A.; Rawlett, A.M.; Tour, J.M. Large On-off Ratios and Negative Differential Resistance in a Molecular Electronic Device. Science 1999, 286, 1550-1552. [CrossRef] [PubMed]

378. Karuppannan, S.K.; Hongting, H.; Troadec, C.; Vilan, A.; Nijhuis, C.A. Ultrasmooth and Photoresist-Free Micropore-Based EGaIn Molecular Junctions: Fabrication and How Roughness Determines Voltage Response. Adv. Funct. Mater. 2019, 29, 1904452. [CrossRef]

379. Wang, G.; Kim, Y.; Choe, M.; Kim, T.W.; Lee, T. A New Approach for Molecular Electronic Junctions with a Multilayer Graphene Electrode. Adv. Mater. 2011, 23, 755-760. [CrossRef]

380. He, J.; Chen, B.; Flatt, A.K.; Stephenson, J.J.; Doyle, C.D.; Tour, J.M. Metal-Free Silicon-Molecule-Nanotube Testbed and Memory Device. Nat. Mater. 2006, 5, 63-68. [CrossRef]

381. Puebla-Hellmann, G.; Venkatesan, K.; Mayor, M.; Lörtscher, E. Metallic Nanoparticle Contacts for High-Yield, Ambient-Stable Molecular-Monolayer Devices. Nature 2018, 559, 232-235. [CrossRef]

382. Preiner, M.J.; Melosh, N.A. Creating Large Area Molecular Electronic Junctions Using Atomic Layer Deposition. Appl. Phys. Lett. 2008, 92, 213301. [CrossRef]

383. Milani, F.; Grave, C.; Ferri, V.; Samorì, P.; Rampi, M.A. Ultrathin $\pi$-Conjugated Polymer Films for Simple Fabrication of Large-Area Molecular Junctions. ChemPhysChem 2007, 8, 515-518. [CrossRef] [PubMed]

384. Li, T.; Hauptmann, J.R.; Wei, Z.; Petersen, S.; Bovet, N.; Vosch, T.; Nygãrd, J.; Hu, W.; Liu, Y.; Bjørnholm, T.; et al. Solution-Processed Ultrathin Chemically Derived Graphene Films as Soft Top Contacts for Solid-State Molecular Electronic Junctions. Adv. Mater. 2012, 24, 1333-1339. [CrossRef]

385. Jeong, H.; Kim, D.; Xiang, D.; Lee, T. High-Yield Functional Molecular Electronic Devices. ACS Nano 2017, 11, 6511-6548. [CrossRef] [PubMed]

386. Karuppannan, S.K.; Neoh, E.H.L.; Vilan, A.; Nijhuis, C.A. Protective Layers Based on Carbon Paint to Yield High-Quality Large-Area Molecular Junctions with Low Contact Resistance. J. Am. Chem. Soc. 2020, 142, 3513-3524. [CrossRef] [PubMed]

387. Nijhuis, C.A.; Reus, W.F.; Barber, J.R.; Dickey, M.D.; Whitesides, G.M. Charge Transport and Rectification in Arrays of SAM-Based Tunneling Junctions. Nano Lett. 2010, 10, 3611-3619. [CrossRef]

388. Jeong, I.; Song, H. Fabrication and Characterization of Graphene/Molecule/Graphene Vertical Junctions with Aryl Alkane Monolayers. J. Korean Phys. Soc. 2017, 71, 692-696. [CrossRef] 
389. Guo, X.; Small, J.P.; Klare, J.E.; Wang, Y.; Purewal, M.S.; Tam, I.W.; Hong, B.H.; Caldwell, R.; Huang, L.; O'Brien, S.; et al. Covalently Bridging-Gaps in Single-Walled Carbon Nanotubes with Conducting Molecules. Science 2006, 311, 356-359. [CrossRef]

390. Cao, Y.; Dong, S.; Liu, S.; He, L.; Gan, L.; Yu, X.; Steigerwald, M.L.; Wu, X.; Liu, Z.; Guo, X. Building High-Throughput Molecular Junctions Using Indented Graphene Point Contacts. Angew. Chem. 2012, 124, 12394-12398. [CrossRef]

391. Supur, M.; Van Dyck, C.; Bergren, A.J.; McCreery, R.L. Bottom-up, Robust Graphene Ribbon Electronics in All-Carbon Molecular Junctions. ACS Appl. Mater. Interfaces 2018, 10, 6090-6095. [CrossRef]

392. Tefashe, U.M.; Van Dyck, C.; Saxena, S.K.; Lacroix, J.C.; McCreery, R.L. Unipolar Injection and Bipolar Transport in Electroluminescent Ru-Centered Molecular Electronic Junctions. J. Phys. Chem. C 2019, 123, 29162-29172. [CrossRef]

393. Najarian, A.M.; McCreery, R.L. Long-Range Activationless Photostimulated Charge Transport in Symmetric Molecular Junctions. ACS Nano 2019, 13, 867-877. [CrossRef] [PubMed]

(C) 2020 by the authors. Licensee MDPI, Basel, Switzerland. This article is an open access article distributed under the terms and conditions of the Creative Commons Attribution (CC BY) license (http://creativecommons.org/licenses/by/4.0/). 